أثر الميط المادى للفدهة على ارتباط العملاء بمراكز

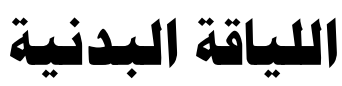

*. نرهين أحمد عبد المنعم السعدنى

* د. نرمين أحمد عبد المنعم السعدنى المدرس بقسم إدارة الأعمالـ كلية التجارة- جامعة القاهرة 


\section{ملخص الارراسة}

تهدف هذه الدراسـة إلى تطوير نموذج يوضـح دورالمحيط المسادى للخدمة كمحدد أساسـي

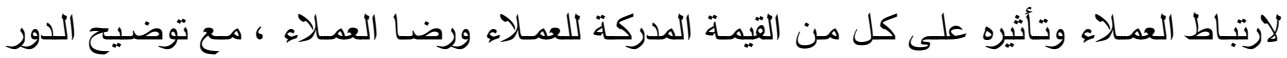

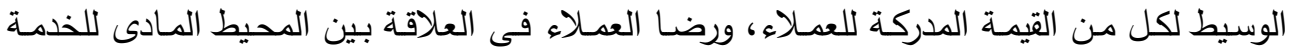

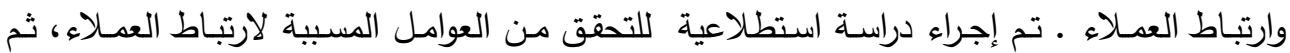

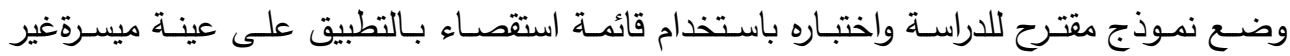

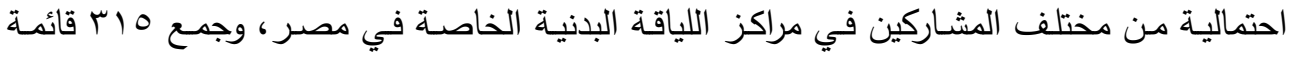
صالحة للتحليل الاحصائى باستخدام نمذجة المعادلة الهيكلية Smart PLS. وتوصلت النتائج إلى هرحئ

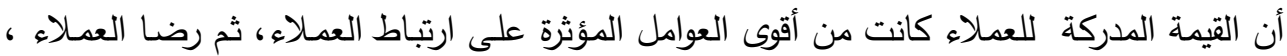

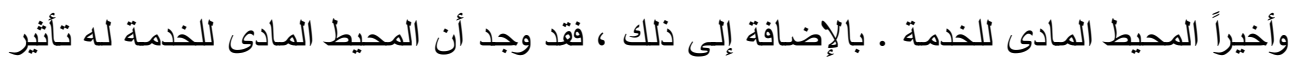
غير مباشر على ارتباط العملاء بتوسيط كل من القيمة المدركة للعملاء ورضا العملاء.

\section{Abstract}

This study aims to develop a model indicates the role of servicescape as a key driver of customer engagement by analyzing its impact on customer percieved value and customer satisfaction and clarifying the moderating role of perceived value and customer satisfaction.

A qualitative exploratory study was conducted at first to investigate the important variables that form Customer engagement . Then, a conceptual framework was developed and tested by the means of survey-based questionnaires. (315) valid questionnaires were collected through a nonprobability convenience sampling technique from different participants in private fitness centers in Egypt. The data were analysed using structural equation modelling on Smart PLS.

The results have shown that customer perceived value was found to have the strongest impact on customer engagement followed by the customer satisfaction, then, servicescape. Additionally, servicescape was found to have a significant direct and indirect impact on customer engagement through the mediating effect of customer perceived value and customer satisfaction. 


\section{مقدمة الاراسة}

يتزايـ الوعي بنمط الحياة الصحي في المجتمع المصري يوماً بعد يوم، وتتمثل إمكانيـة

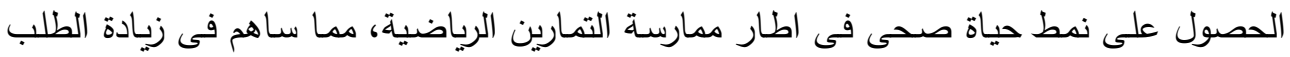

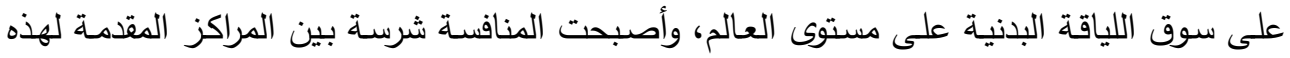
الذدمة للحفاظ على العملاء (Oztas et al., 2016)، الذين يبحثون بدورهم باستمرارعن عوامل

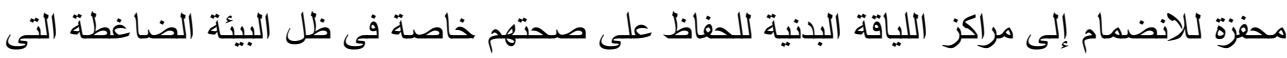

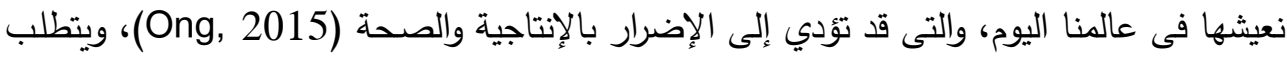

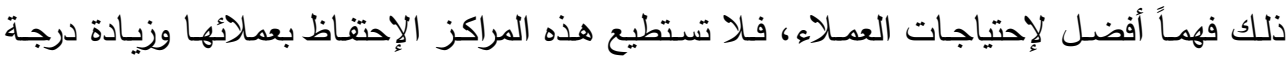

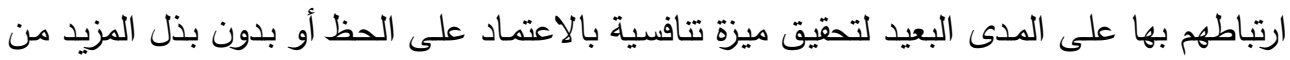

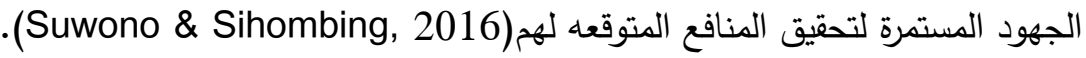
فمن أجل الحفاظ على العملاء وزيادة ارتباطهم بشكل مميز يجب على العي المنظمات الاهتمام

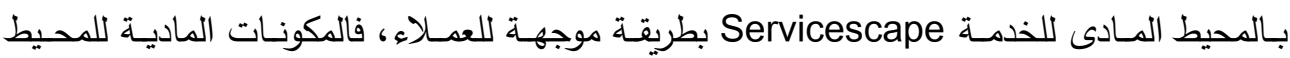

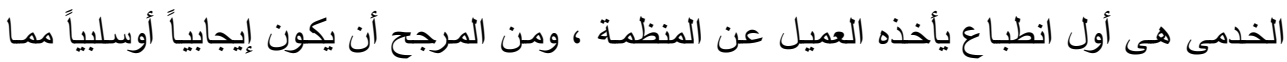
يؤثر على سلوكهم فى البقاء أوالابتعاد عن المنظمـة، وهذا مـا تفسره النظريـة السلوكية (الهثير والاستجابة) (Mehrabian and Russell, 1974)، والتى توضح كيف تؤثر المثيرات الحسية

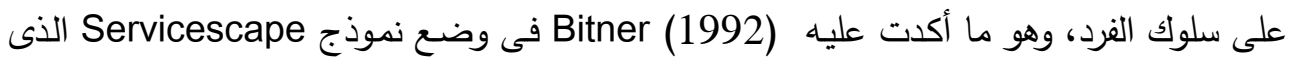

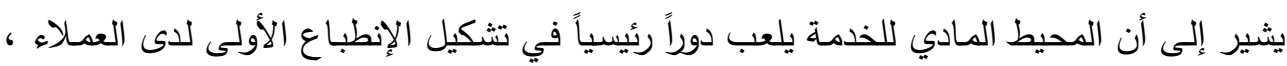

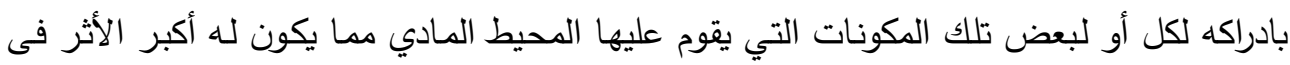

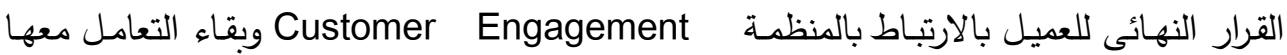

. (Dovaliene et al., 2015)

ساهم ذلك فى دفع الكثير من الباحثين والممارسين للاهتمام بارتباط العملاء على نطاق

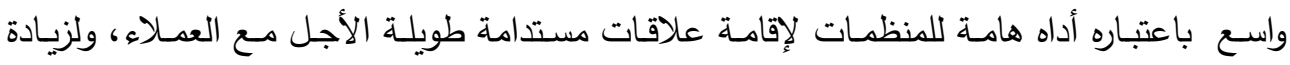

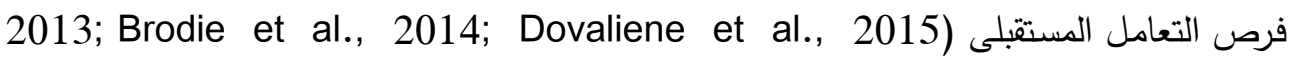
(Hapsari et al., (Hollebeek et al., (2017.وبناءً عليه أجريت العديد من الدراسات حول ارتباط العملاء بالتطبيق على القطاع الخدمى، كالفنادق والطيران (So et al., 2012, 2014)، ومواقع الإنترنت ووسائل الإعلام الاجتماعية العاعية 
(Calder et al., 2009; Hollebeek et al., 2014) .(Sprott et al., 2009; Vivek et al., 2014) وبالرغم من وفرة الأبحاث حول ارتباط العملاء ، إلا إنه لا يزال مجالاً خصباً يمثل أهمية

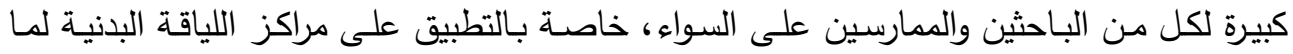

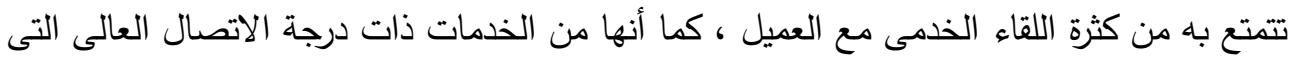

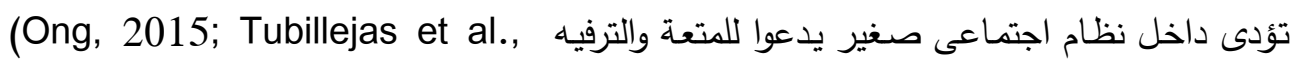

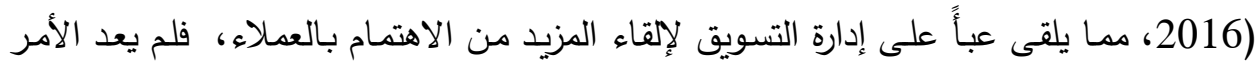

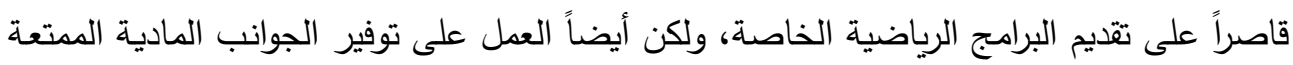

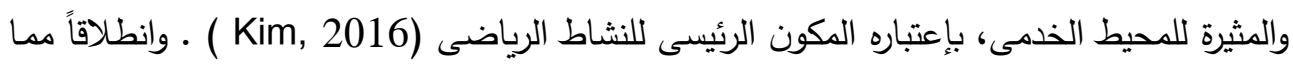
سبق تهدف الدراسة الحالية لإلقاء المزيد من الضوء حول علاقة العملاء بالبيئة من خلال دراسة تأثير الدحيط المادى للخدمة Servicescape على ارتباط العملاء بمراكز اللياقة البدنية وتوضيح دور كل من رضا العملاء والقيمة المدركة كمتغيرات وسيطة. أولاً: الإطار النظري للدراسة سيتم عرض الإطار النظري للدراسة على محورين أساسين هما المفاهيم الإجرائية لمتغيرات الدراسة، والدراسات السابقة وصياغة فروض الإنمانة الدراسة. ا - المفاهيم الإجرائية لمتغيرات الدراسة

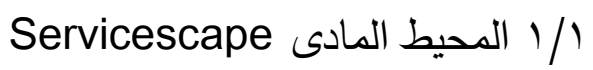
يعرف المحيط المادى للخدمة على أنه "المناخ أوالبيئة التي تقدم فيها الخدمة والتي يتفاعل

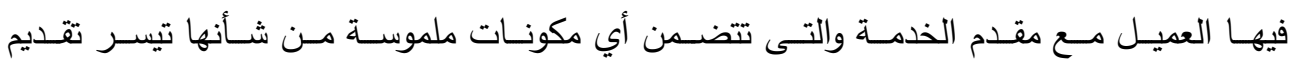
الخدمة(Binter, 1992:62) ، كما تعرف على أنها الطبيعة المصطنعة من قبل الإنسان كمقابل

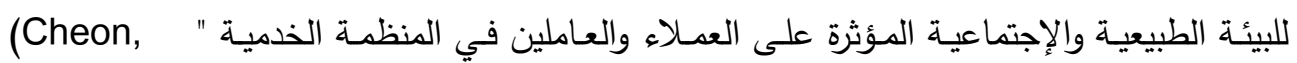

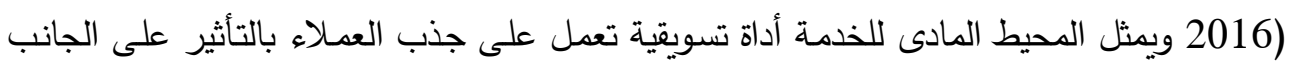

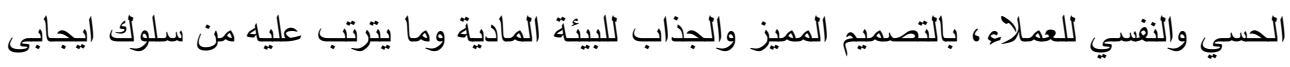
للعملاء (Jain \& Bagdare, 2011) ، كما أنه يساعد فى تحفيز وتتشيط أداء مقدمى الخدمة

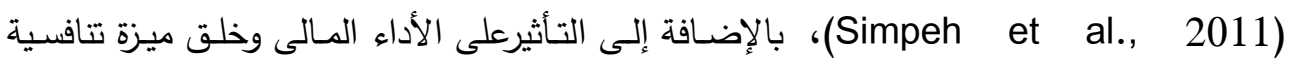

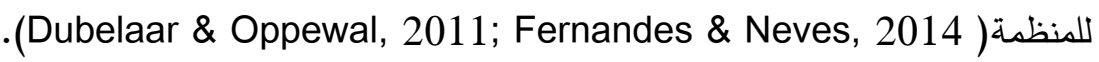


فالمحيط المادى للخدمة يشار إليه على أنه من أكثر العوامل الهامة والمؤثرة على سلوك

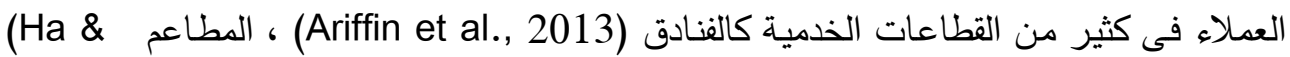

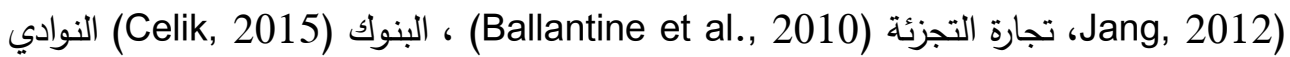
الرياضية ومراكز اللياقة البدنية (Suwono \& Sihombing, 2016)

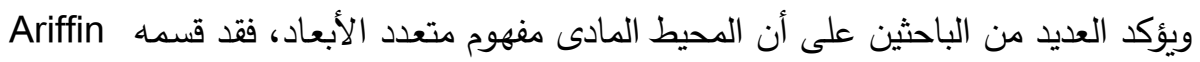

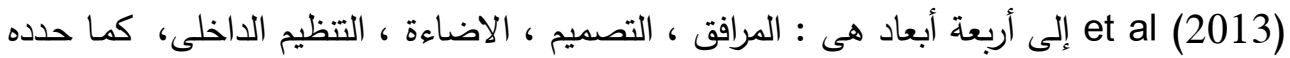

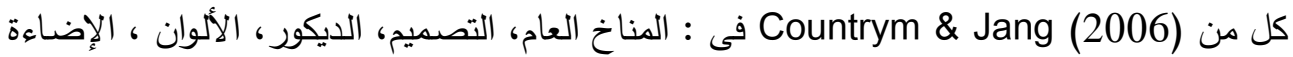

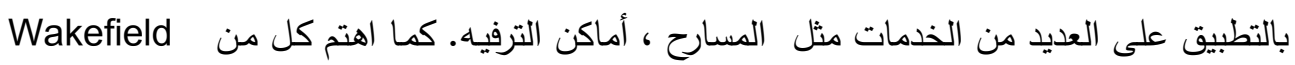

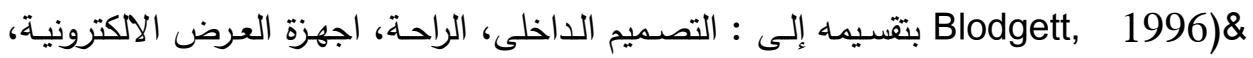
الأجهزة، النظافة، بالتطبيق على الخدمات الرياضية. ويعتبر تقسيم (1992) من Bitner من أكثر التقسيمات شيوعاً وتتظيماً والتى لاقت قبولاً بين (Medabesh\& Upadhyaya, 2012; Ishaq et al.,2014; Rashid et الباحثين al.,2015) والذي يعتمـد على تقسيم المحيط المـادى للخدمـة إلى ثلاثـة أبعـاد وهـى المنـاخ

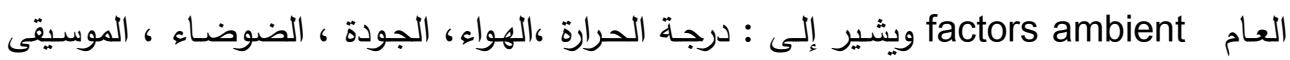

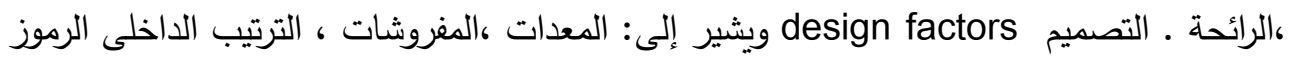
والعلاماتsymbols \& Signs وتشير إلى :اللوحات الارشادية ،الصور ،الديكور .

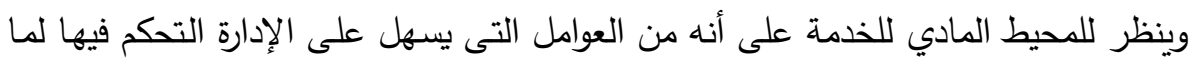

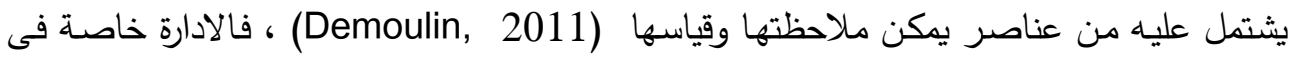

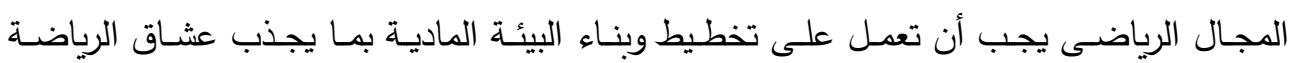

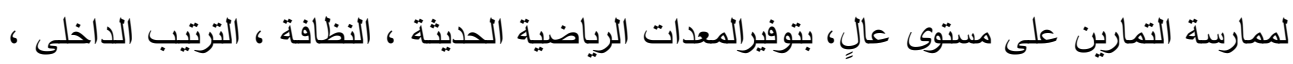
الرائحة، ودرجة الحرارة، التصميم الداخلى ، والديكور المناسب (Polyakova \& Mirza, 2016).

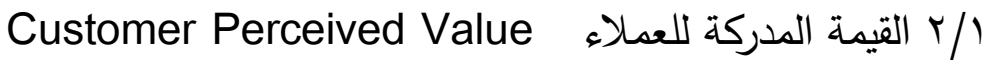
تعرف القيمة المدركة للعميل على أنها" ما يعتقد أن يحصل عليه العميل من منافع محققة

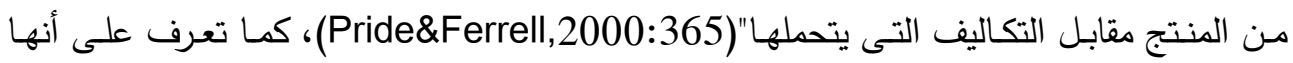

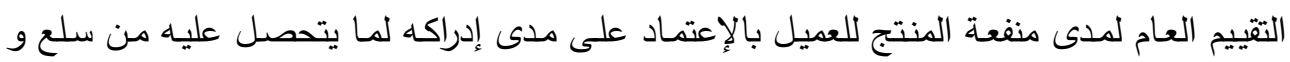

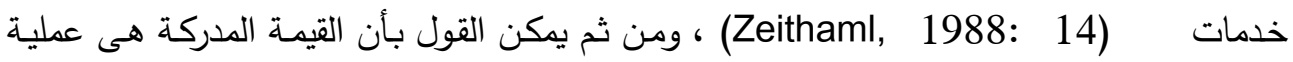


مقارنة بين المنافع التى يحصل عليها العميل والتكاليف التى يتحملها فى سبيل حصوله على المنتج،

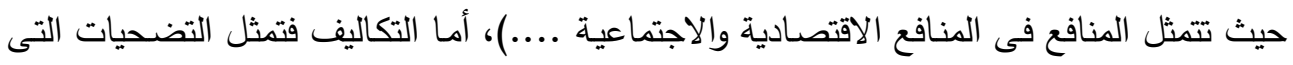

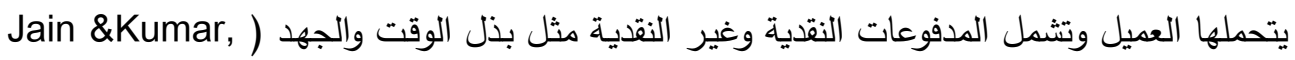
2015). وتمثل القيمة المدركة معيارًا هامًا في تطوير الاستراتيجيات الإدارية لما لها من تأثير على لفئل

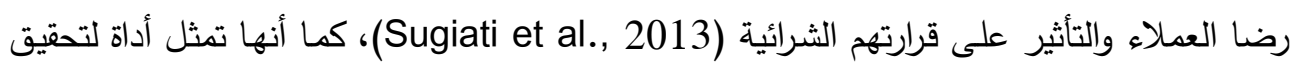

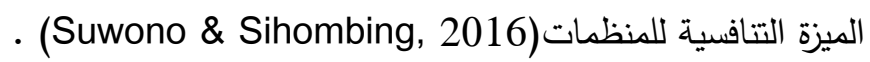

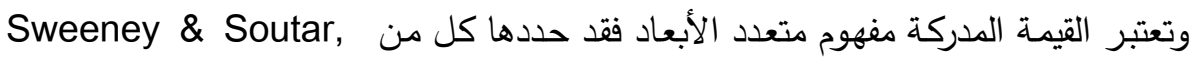

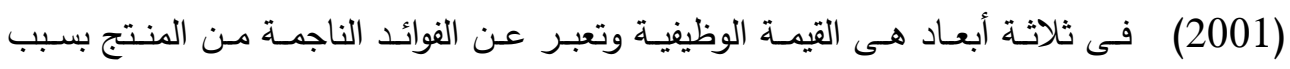

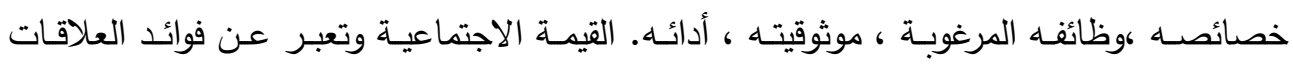

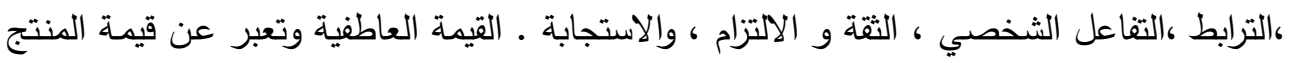

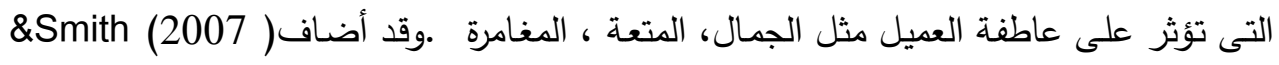
Colgate et al., 2013)

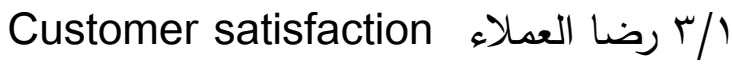

يمثل رضـا العمـاء التقييم العـام للمنظمـة ومنتجاتها فهو يعبر عن مدى مطابقة منتجات المنظمة لتوقعات العملاء (Kim et al., 2013) فقد عرف Kotler 2009:143) رضاء العميل

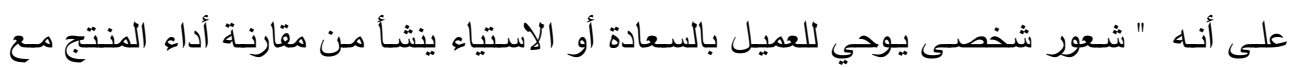

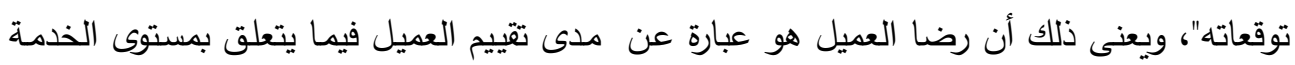
المقدمة لله مقارنة بتوقعاته.

ويستحوذ رضـا العميل على أهميـة كبيرة لدى الكثير مـ المنظمـات ويعـد مـن أكثر

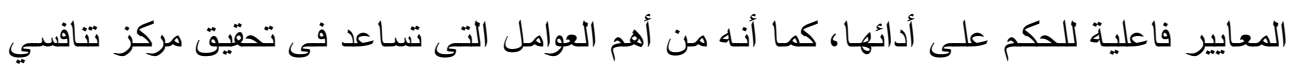

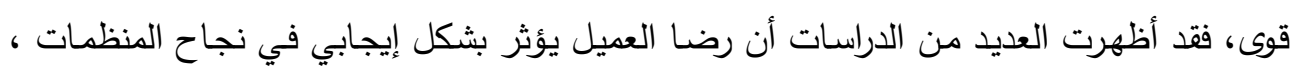

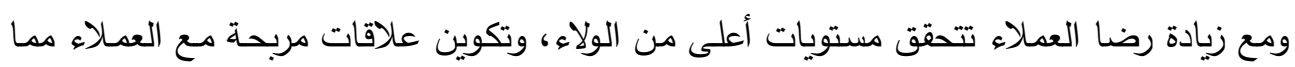

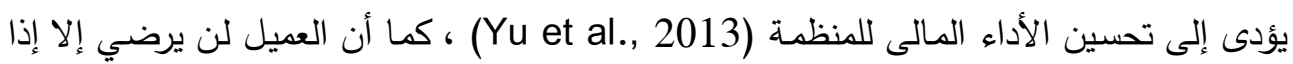
كانت منافع المنتجات أو الخدمات تفوق توقعاته (Ariff et al., 2012). 


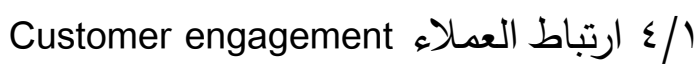
يعد مفهوم ارتباط العمـلاء من المفـاهيم التى اهتم بها الفكر التسويقى فى الآونـة الأخيرة هذا (Brodie et al., 2013; Hollebeek et al.,2014; Quynh et al., 2018)

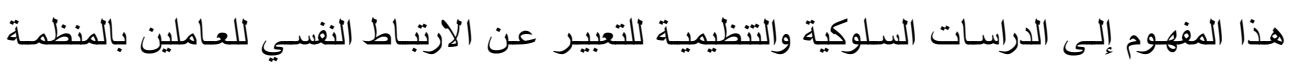
(Schaufeli et al, 2002;Mohr and Webb, 2005)، ثم انتقل هذا المفهوم إلى الدراسات التسويقية وظهر مصطلح "ارتباط العملاء" Customer engagement للتعبير عن الارتباط النفسى للعملاء بالمنظمة.

ويعرف ارتباط العملاء بأنه "المظاهر السلوكية للعميل تجاه شركة أو علاهمة تجاريـة محددة

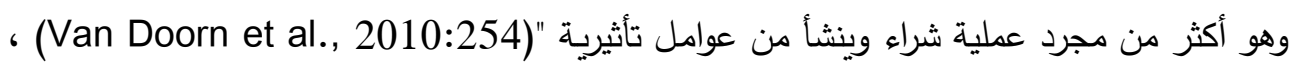

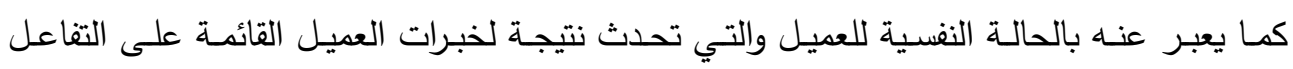
والمشاركة ميع المنظمة (Brodie et al., 2011)، كما يشير إلى أي سلوك يرتبط بالعلامـة

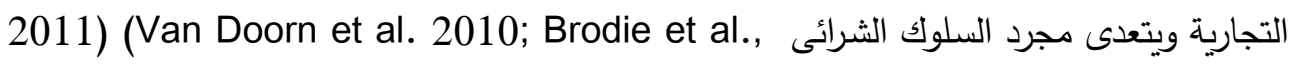
ويشمل ارتباط العملاء الكلام الشفهي ، واقتراحات التحسين والتطوير للمنظمة، والمشاركة النشطة

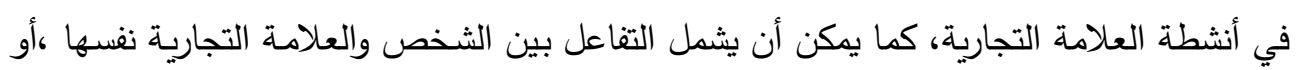
بين الأشخاص فيما يتعلق بالعلامة التجارية (Bijmolt et al., 2010).

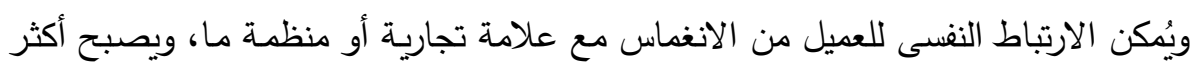

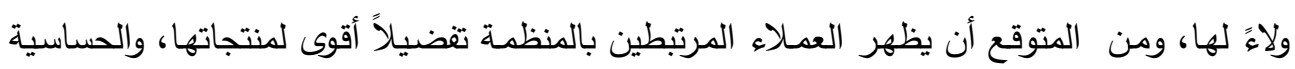

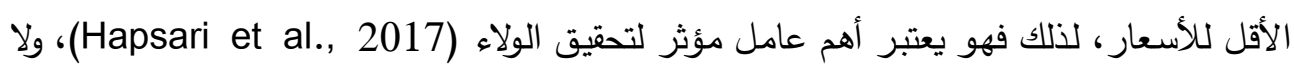

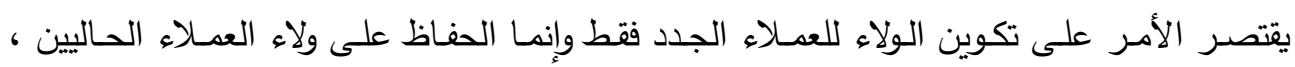

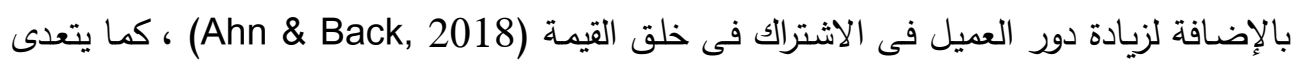

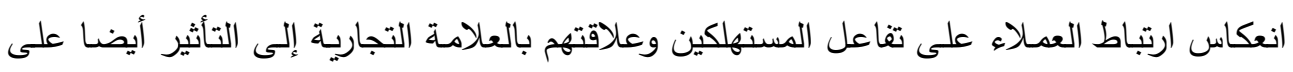

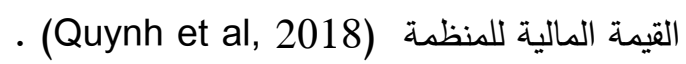
وينظر لارتباط العملاء على أنه من المفاهيم متعددة الأبعاد وقد تبنت الدراسات السابقة أبعاد

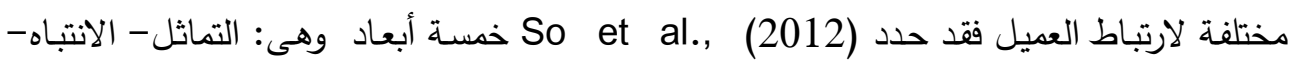
الحماس-الانغماس- التفاعل .وقد اتفق العديد من الباحين على ثلاثة أبعاد رئيسية لارتباط العميل

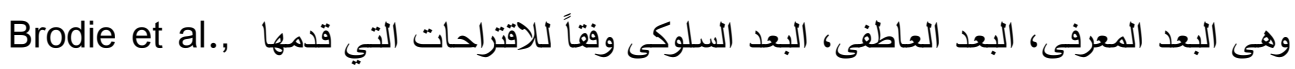


(2011) يشير البعد المعرفى إلى تبادل خبرات العيل مـع العملاء الآخرين، وأن يكون فى حالة

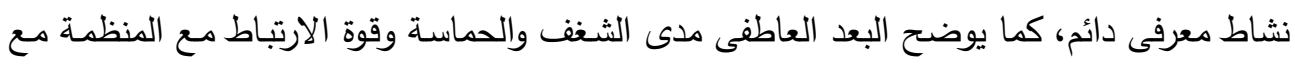

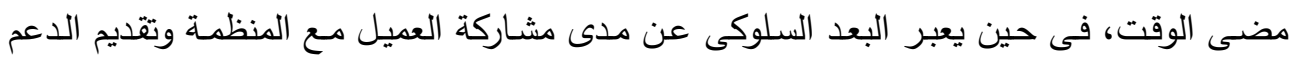

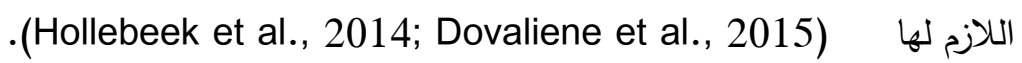
r-الدراسات السابقة وصياغة فروض الدراسة. سيتم عرض الدراسات السابقة التى توافرت للباحث وصياغة فروض الدراسة من من خلال تقسيم الدراسات اعتماداً على العلاقة بين متغيرات الدراسة على النحو التالى : r/ الدراسات التى تناولت العلاقة بين المحيط المادى للخدمة وارتباط العملاء. أظهرت العديد من الدراسات أن أبعاد المحيط المادي للخدمات لها تأثير قوي على سلوك واتباه

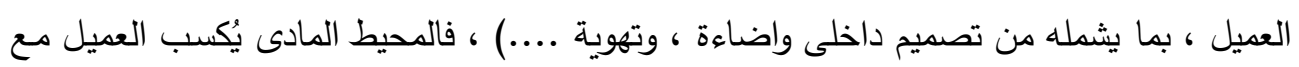

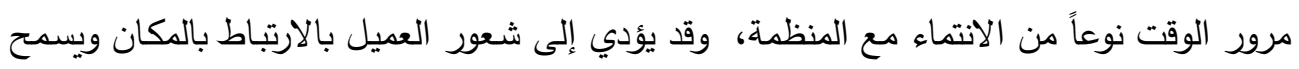
ذلك بظهور الرغبة في العودة لله مستقبلا دون تردد (Chen et al.,2015; Yap, 2017)

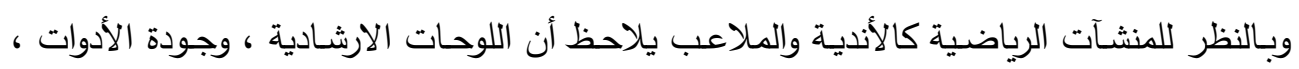

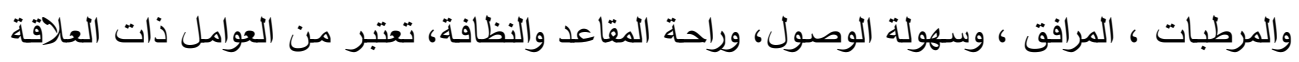
الايجابية بسلوك المشجعين فى الملاعب (Jeon and Kim, 2012). وقد أكدت على ذلك دراسة (Ong et al., 2017) التى اختبرت التأثير المباشر لأبعاد محيط الخدمة لمراكز اللياقة البدنيةعلى سلوك العملاء بالإضـافة للتأثير غير المباشر من خـلاد

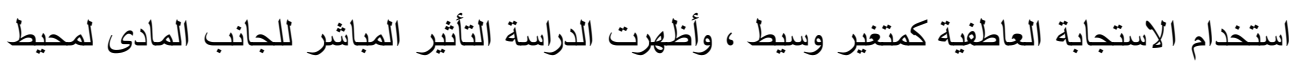

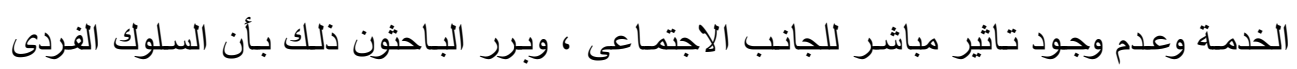

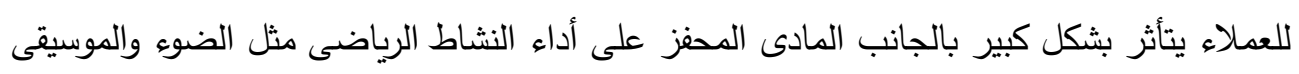

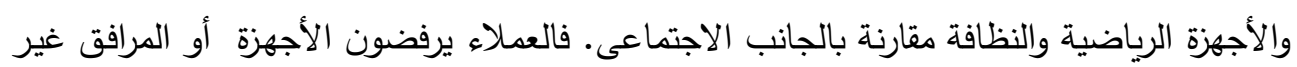

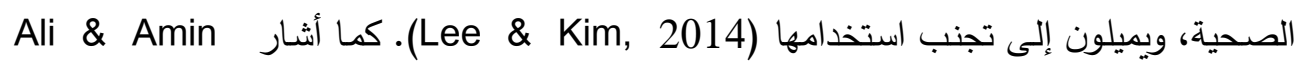
(2014) أن البيئة المادية لها أقوى التأثير على مشاعر العملاء، ولكن ليس بالضرورة أن يكون التأثير ايجابى على السلوك. وبناءً على ذلك يمكن صياغة الفرض الأول على النحو التالى:

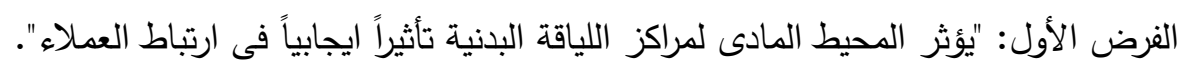


r/ الدراسات التى تتاولت العلاقة بين المحيط المادى للخدمة والقيمة المدركة ورضـا العملغ (1)

يتأثر العملاء بالعديد من العوامل عند انجاز خدمة ما ويعتبر المحيط المادى للخدمة من

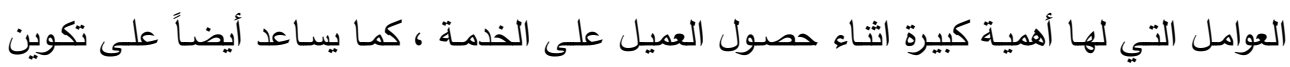
الانطباعات لدى العملاء عن المنظمة ومنتجاتها، فتلجأ المنظمات الخدمية لإستخدام الدلائل المادية أو العناصر الملموسة لجذب العملاء (Lee \& Kim, 2014).

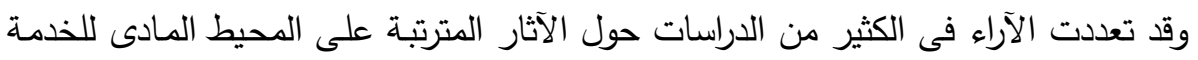

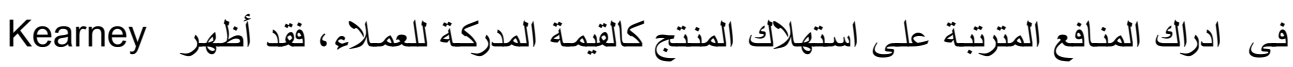
(2013) مدى مساهمة العناصر الداخلية للمحيط المادى للخدمة مثل الرائحة وجودة الهواء والنظافة

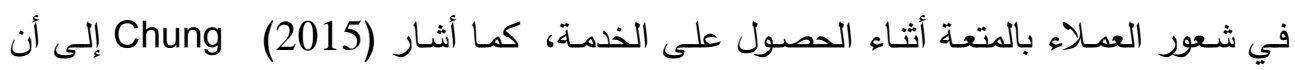

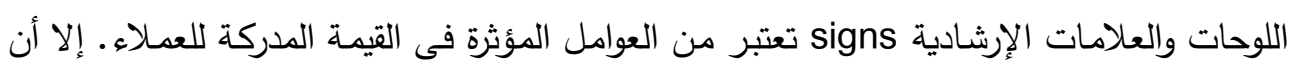
دراسة Shashikala \& Suresh (2018) أظهرت عدم تأثير العناصر الخارجية - أماكن

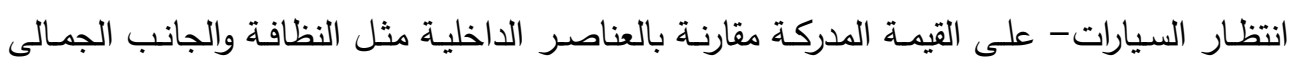

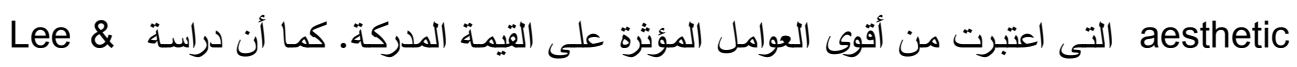

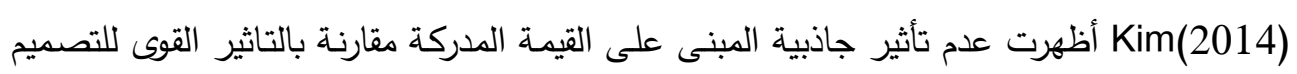
الداخلى للخدمات العامة. واهتمت العديد من الدراسات باكتشاف الأثر الإيجابى للجانب المادى للمحيط الخدمى فى العى

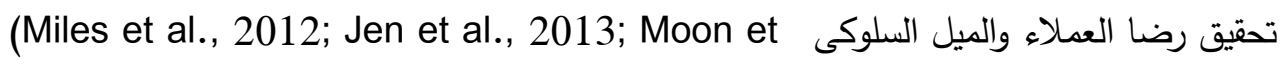

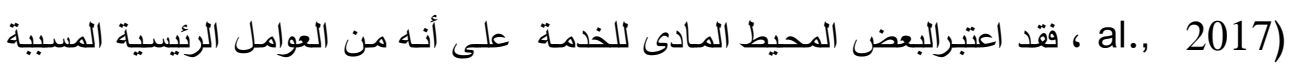

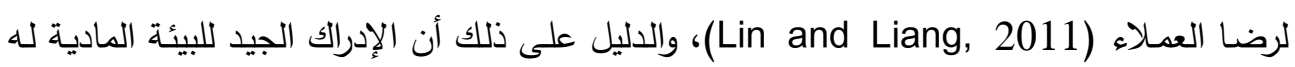

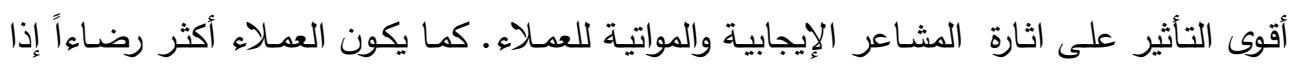

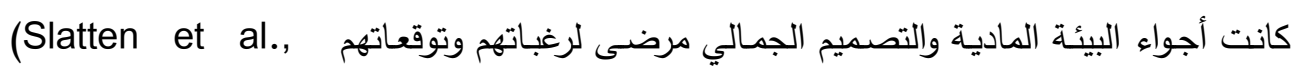
2011;Ha \& Jang, 2012, Ali \& Amin, 2014) العملاء مثل عدم وجود أدوات حديثة، أوالشعور بعدم النظافة فإنه يولد شعوراً بالإستياء وعدم الرضا لإلة

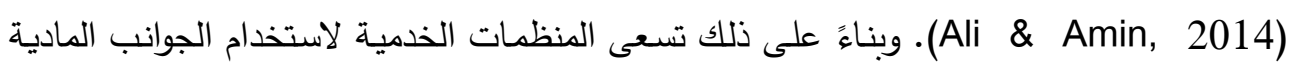

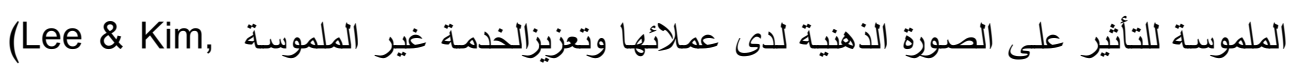
ITV 
(2014. وبالنظر إلى المراكز الرياضية نجد أن العناصر المادية المكونـة للخدمة تعتبر من أهم

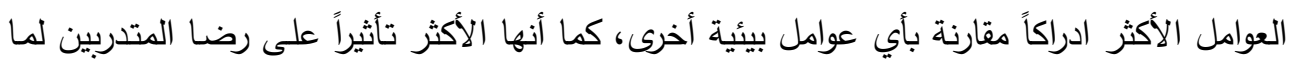

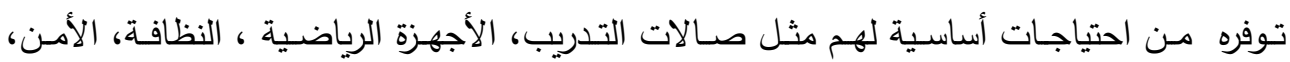

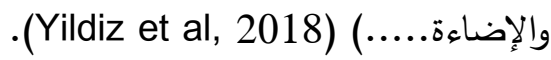

وتلقى دراسـة Salamat et al (2013) الضوء على أثر المحيط المادى على رضا

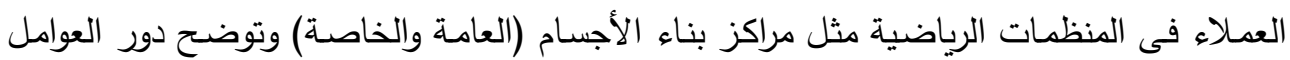

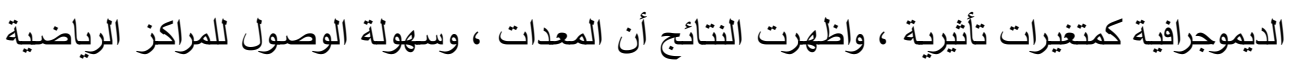

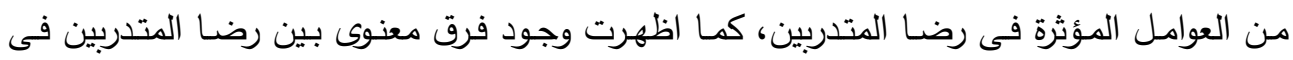
المراكز العامة والخاصة، مع الاشارة إلى عدم وجود فروق معنوية فى رضا المتدربين رضين وفقاً للنوع.

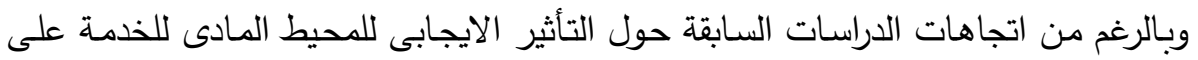
رضا العملاء إلا أن دراسة (2016) Suwono \& Sihombing أوضحت عدماتئ عدات وجود علاقة بين

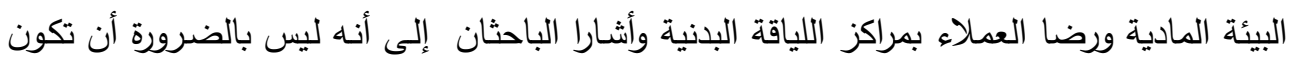

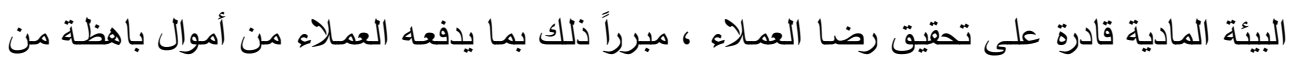
أجل الحصول على بيئة مادية جيدة الأمر الذى من شأنه يقلل من رضات العاء العملاء.

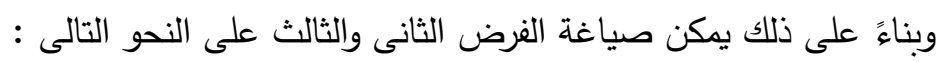

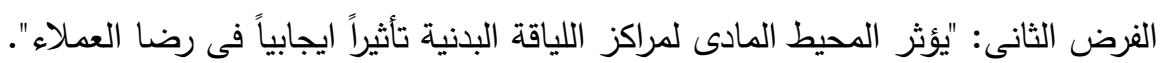
الفرض الثالث: "يؤثر المحيط المادى لمراكز اللياقة البدنية تأثيراً ايجابياً فى القيمة المدركة للعملاء". r/r/الدراسات التى تناولت العلاقة بين القيمة المدركة ورضا العملاء.

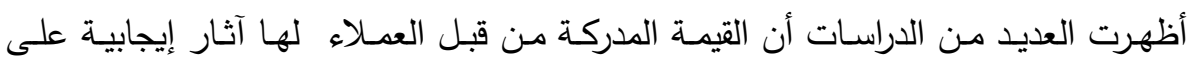
رضائهم (Kim et al., 2012; Sohn and Yoon, 2013; Shin, 2014)، فقد أثبتت دراسة فئس أن القيمة المدركة تعتبر أقوى محدد لرضا العملاء (McDougall \& Levesque, 2000 ) وذلك في دراسة تجريبية للعديد من الخدمات كالمطاعم، تصليح السيارات، تصفيف الثعر والخدمات

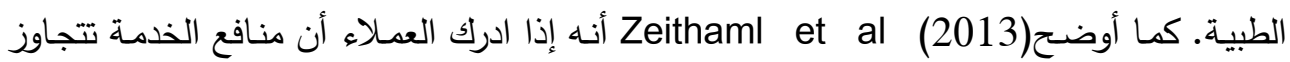

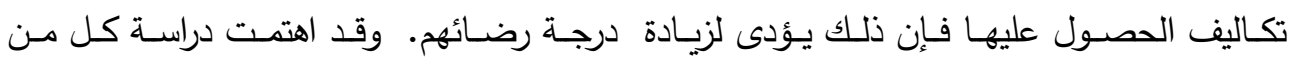
بتوضيح العلاقة بين القيمة المدركة ورضا (Rozenes \& Cohen, 2017; Yu et al., 2014) العملاء بالتطبيق على الخدمات الرياضية واشارات الدراسات إلى أن القيمة الددركة تعتبر مؤشر هام 
لرضا العميل ، فالمستوى الأعلى من القيمة المدركة يحقق مستوى أعلى من رضا العملاء، بالإضافة

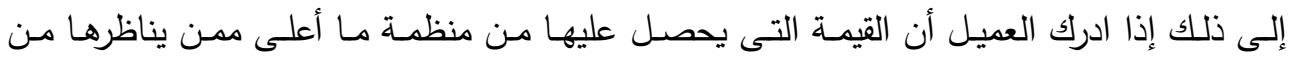
منظمات منافسة فإنه يولد لديه الشعور بالرضا (Sugiati et al., 2013).

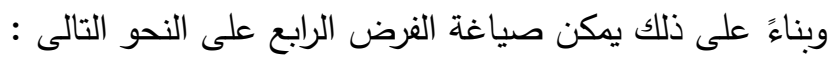

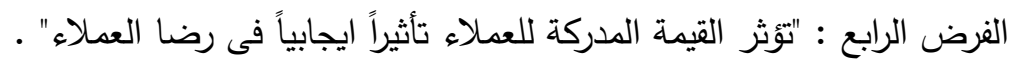

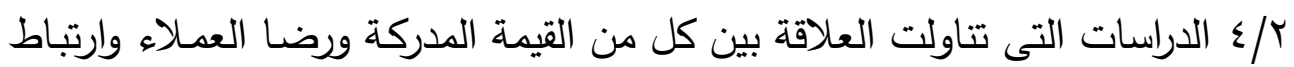

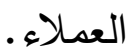
يعتبر كـل مـن القيمـة المدركـة ورضــا العمـلاء مـن العوامـل المؤثرة فـى ارتبـاط العهـلاء

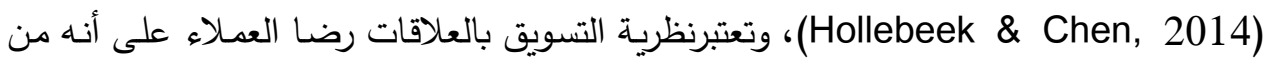

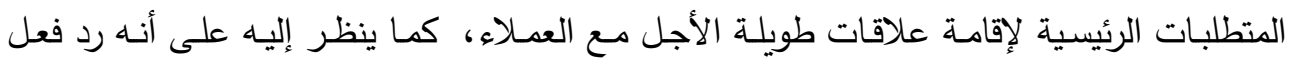
عاطفي ينشأ من التعامل مع العملاء (Quynh et al 2018) ، وتشير الدراسات إلى أن القيمة

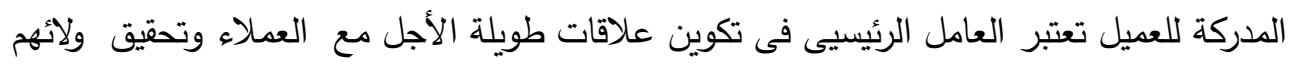
.(Ariff et al., 2012; Khan, 2013; Sugiati et al., 2013) كما جاء فى دراسة (Hapsari \& Dean, 2017) التى أثبتت تأثير القيمة الدركة على ارتباط

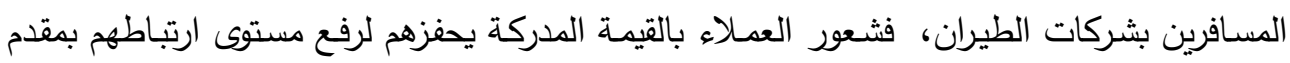
الخدمة ، إما لأسباب نفسية أو لكسب المزيد من القيمة مستقبلاً. إلا أن دراسة(Dovaliene et al.,2015) أظهرت العلاقة المتبادلة بين ارتباط العملاء والقيمة المدركة بالتطبيق على تطبيقات(Apps) التليفون المحمول، وأن الأبعاد السلوكية والعاطفية

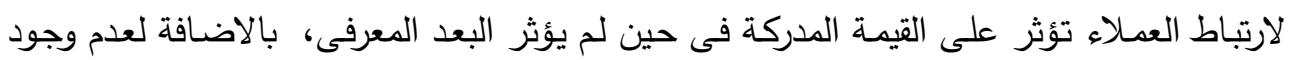

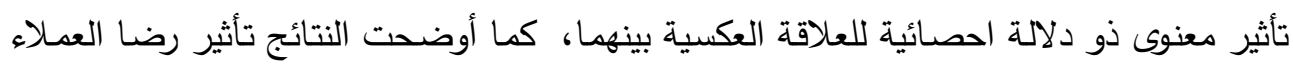

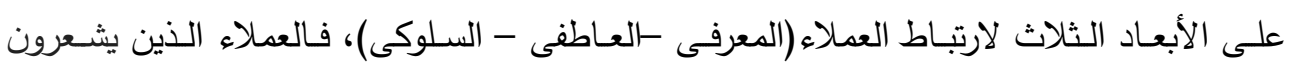

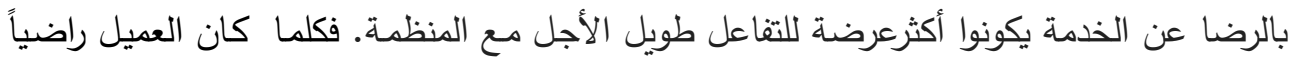

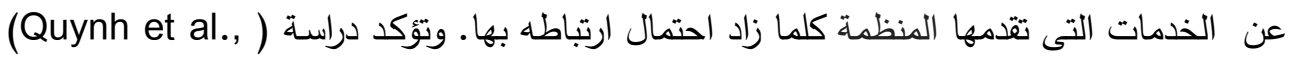

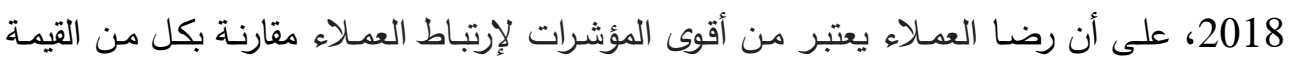

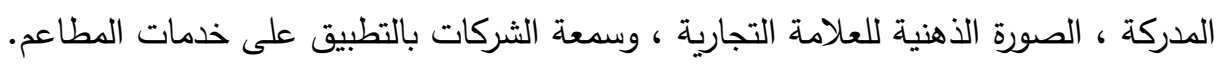
وبناءً على ذلك يمكن صياغة الفروض التالية كما يلى : 
الفرض الخامس : يؤثر رضا العملاء تأثيراً إيجابياً فى ارتباط العملاء.

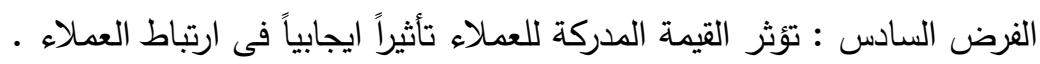

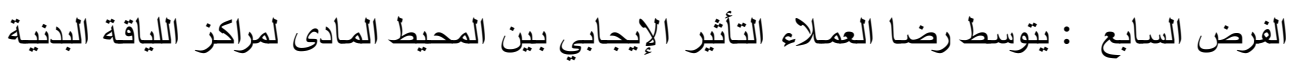
وارتباط العملاء. الفرض الثامن تتوسط القيمة المدركة للعملاء التأثيرالإيجابي بين المحيط المادى لمراكز اللياقة البدنية وارتباط العملاء. ثانياً: مشكلة الاراسة وارتبة العملاء

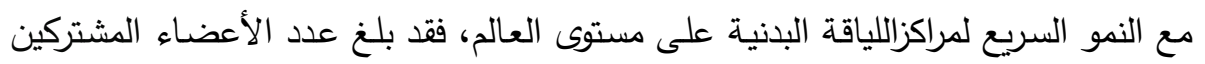

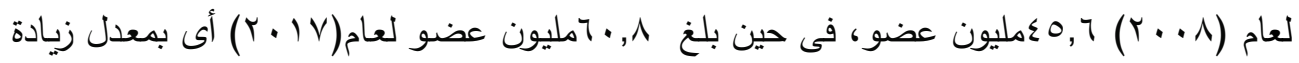

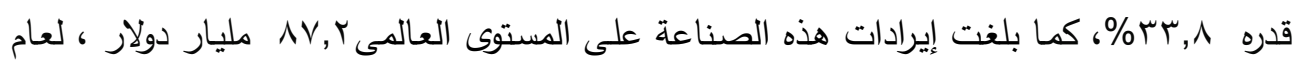
- (IHRSA, 2017) (r.IV)

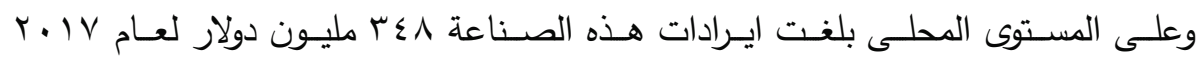

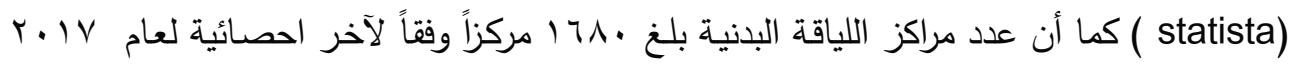

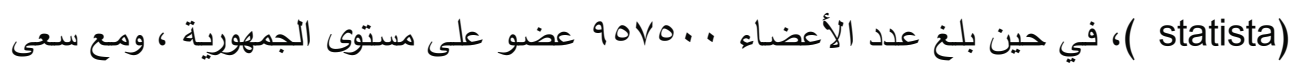

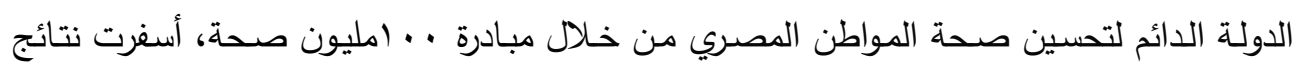

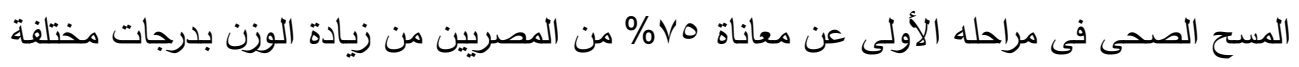

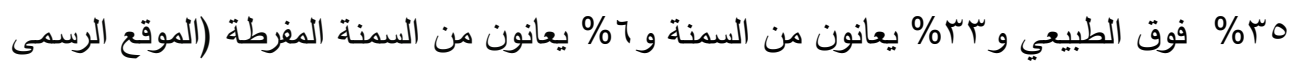
لوزارة الصحة والسكان، 1 ( • ب).

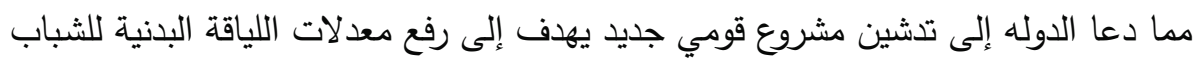

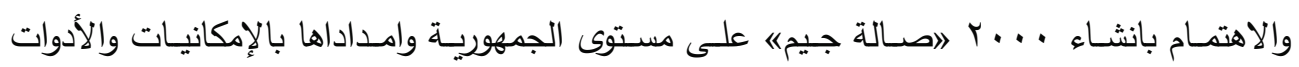

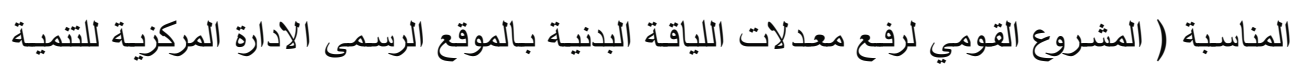

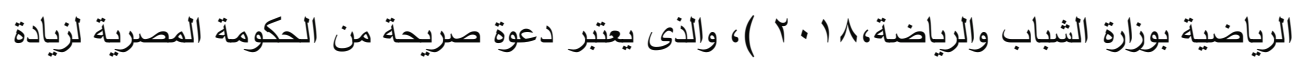
ارتباط المواطنين بمراكز اللياقة البدنية.

الأمر الذى زاد من أهمية البحث لتحديد أهم العوامل المؤثرة على ارتباط العملاء بمراكز

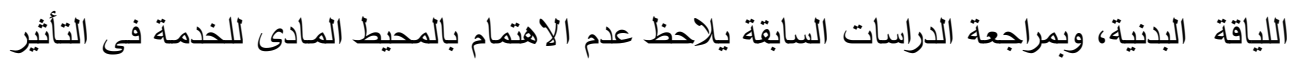

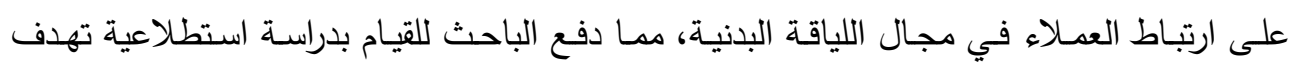


لمعرفة أهم العوامل المؤثرة على ارتباط العملاء بمراكز اللياقة البدنية الخاصسة على عينـة مكونـة من • ب مفردة ، وقد وافقت نسبة كبيرة منهم على أن الديكورودرجة الحرارة والموسيقى والإضاءة والنظافة

$$
\text { لعبت دوراً رئيسياً في ارتباطهم بالمركز . }
$$

ومن ثم يمكن توضيح مشكلة الدراسة فيما يلى:

"دراسة أثر المحيط المادى للخدمة فى تحقيق رضا العملاء والقيمة المدركة وسلوك ارتباط العملاء

بمراكز اللياقة البدنية".

ثالثاً: أهداف الدراسة

يعد الهدف الرئيسى للبحث هو دراسة أثر المحيط المادى للخدمة فى سلوك ارتباط العملاء بالتطبيق على مراكز اللياقة البدنية، ويتحقق هذا الهدف من خلال مجموعة من الأهداف الفرعية كما يلي: ا . قياس مستوى ادراك أعضاء مراكز اللياقة البدنية الخاصـة للمحيط المادى للخدمة بأبعاده

$$
\text { الثلاث. }
$$

Y. قياس مستوى رضا الأعضاء وادراكهم للقيمة وارتباطهم بمراكز اللياقة البدنية. r. اختبارمدى التأثيرالمباشـر وغير المباشـر للمحيط المـادى على ارتباط الأعضـاء بمراكز اللياقة البدنية.

ع. تحديد أكثر متغيرات الدراسة تأثيراً على ارتباط العملاء. ه. تحديد دور رضا العميل والقيمة المدركة كمتغيرات وسيط فى العلاقة بين البيئة المادية

$$
\text { رابعاً: أهمية الاراسبة العملاء. }
$$

$$
\text { تبرز أهمية هذا الدراسة من عدة زوايا أساسية هي :- }
$$

ا. ـ الاهتمـام بربط المحيط المـادى للخدمـة بارتباط العمـلاء والذى يمثل التأثير الأكبر على ولاء العمـلاء مقارنـة بـالمتغيرات الأخـرى، والذى قد يكـون لـه تأثيراً ايجابياً على الأداءالمالى للمنظمة (Hapsari et al., 2017). r. التطبيق على مراكز اللياقة البدنية التي تساعد على تحسين نوعية الحياة فى المجتمع، مما

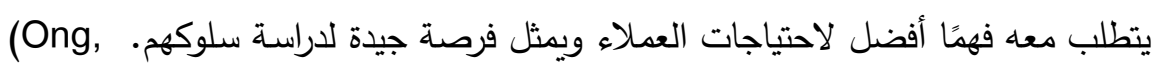
.2015; Polyakova \& Mirza, 2016) 
r. عدم وجود توافق في الآراء العلمية حول الأسباب المؤدية لارتباط العملاء Dovaliene) et al., 2015; Quynh et al 2018)

ـ. تــوفر الدراســة الحاليـة أدلـة علميـة مفيـدة لمصـمي الـديكور الـداخلي ومـديري مراكـز اللياقة|لبدنية، بأهمية العديد من العناصر المادية فى ارتباط العملاء، كما تساعدهم على فهم محفزات الرضا وارتباط الاعضاء المشتركين فيه (Hapsari et al., 2017). ه. توفر الدراسـة نموذجاً لمديري مراكز اللياقة البدنية يسهل من خلاكه قياس ارتباط العمـلاء والتتبؤ به مما يساعد على سرعة اتخاذ القرارات.

\section{خامساً: نموذج الدراسة}

في ضوء العرض السابق يمكن تميثل متغيرات الدراسة والعلاقات بينها في النموذج الموضح في

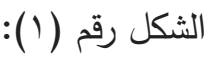

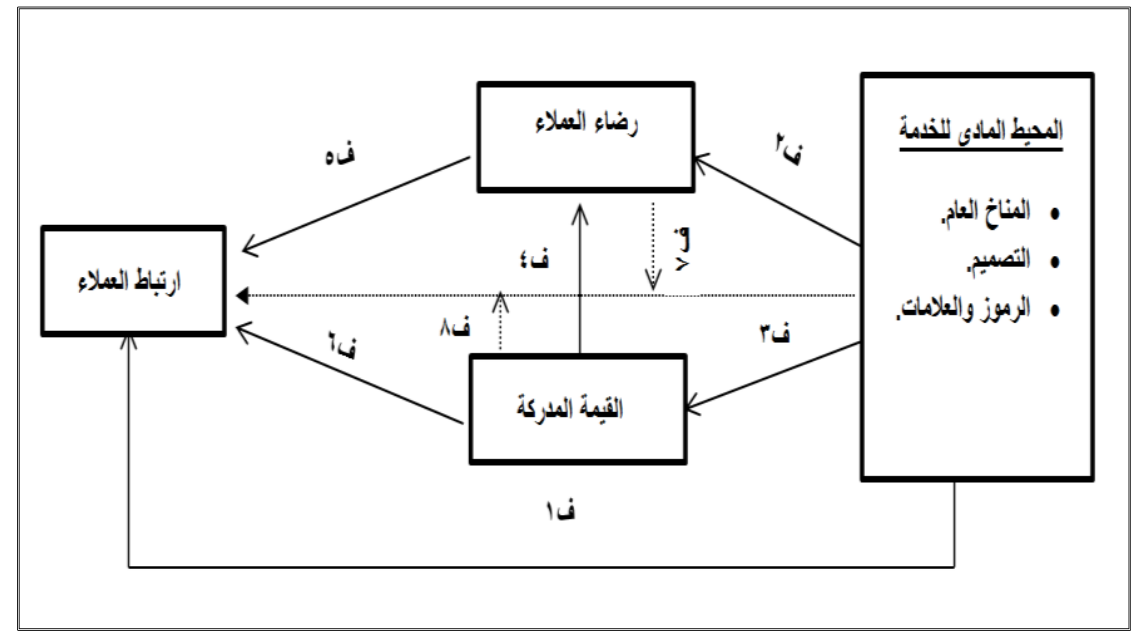

$$
\text { "يتيتيز }
$$

سادساً:منهجية الدراسة 1- 1 - مجتمع وعينة الدراسة

يتألف مجتمع الدراسة من جميع أعضاء مراكز اللياقة البدنية الخاصة والذين تتراوح أعمارهم

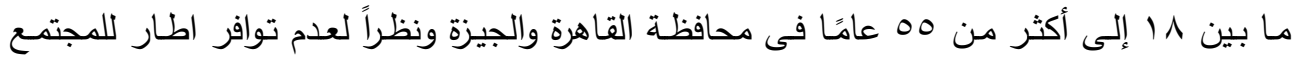


يمكن الاعتمـاد عليه بدقة، تم سحب عينة غير احتمالية ميسرة من الأعضـاء بشرط الا تقل مدة العضوية عن 1 أشهر للمراكز الرياضية الخاصة بهم لضمان قدرتهم على ملىء القائمة وفقاً للاسئلة الواردة بها بدقة.

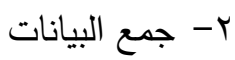

تم جمـع البيانـات باستخدام قائمسة استقصـاء مصممة لهذا الغرض وتوزيـع ^هـ قائمـة على

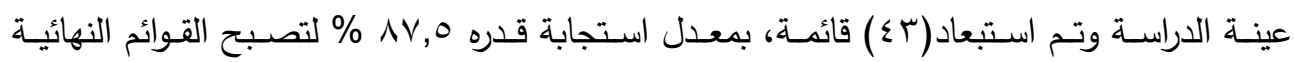
الصالحة للتحليل الإحصـائي ها اسائمة، ويمكن توصيف عينـة الدراسـة كما في الجدول رقم (1)،

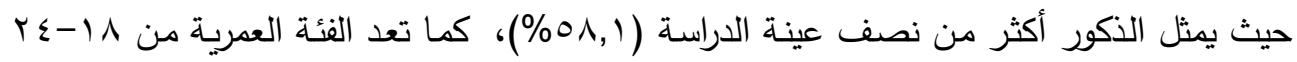

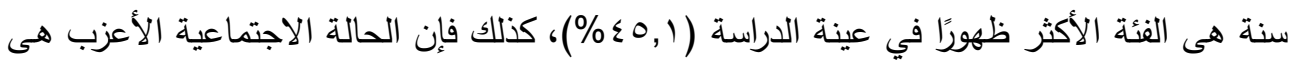
النسبة الغالبة فى عينة الدراسة (10,^\%\%).

جدول (1) خصائص عينة الدراسة

\begin{tabular}{|c|c|c|c|c|c|}
\hline النسبة \% & الت التكرار & الخصائص & النسبة \% & التكرار & الخصائص \\
\hline \multicolumn{3}{|c|}{ السن ل } & \multicolumn{3}{|c|}{ الحالة الاجتماعية } \\
\hline 45.1 & 142 & $18-24$ & 65.8 & 204 & أعزب \\
\hline 37.8 & 119 & $25-34$ & 29.7 & 97 & متزوج \\
\hline 13.0 & 41 & $35-44$ & 2.6 & 8 & مطلق \\
\hline 4.1 & 13 & $45-54$ & 1.9 & 6 & ارمل \\
\hline 315 & 100.0 & الإجمالي & 100.0 & 315 & الإجمالي \\
\hline \multicolumn{6}{|c|}{ النوع } \\
\hline 58.1 & 183 & & & & ذكر \\
\hline 41.9 & 132 & & & & أنثى \\
\hline 100.0 & 315 & & & & الإجمالي \\
\hline
\end{tabular}

"الجدول من اعداد الباحث من واقع الدراسة الميدانية

$$
\text { r- المقاييس المستخدمة في الدراسة }
$$

تم تطوير قائمة استقصاء لقياس المتغيرات التي تضمنها النموذج المقترح للدراسـة بالإعتماد على مجموعة من المقاييس بعد التأكد من ثباتها Reliability وصدقها Validity فى العديد من الدراسـات وإدخـال بعض التعديلات عليها لتلائم مجال التطبيق والواقع العملى بالبيئة المصـرية، وعرضها على مجموعة من الباحثين والمختصين فى مجال التسويق لإبداء ملاحظاتهم والاسترشاد 
بها فى اختبار بنود القائمسة على عينـة تبلغ • ب مفردة وذلك لتعديل أو حذف بعض العبارات التى تبدو غريبة على المستقصى منهم وقد اشتملت القائمة على الأقسام التالية:

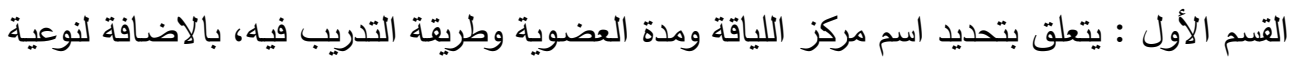

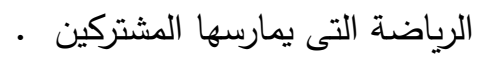
القسم الثانى : يتعلق بأبعاد المحيط المادى للخدمة باستخدام مقياس "ليكرت الخماسي"والذئى يتدرج

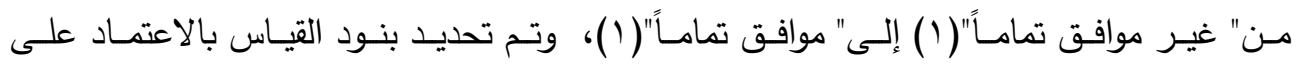

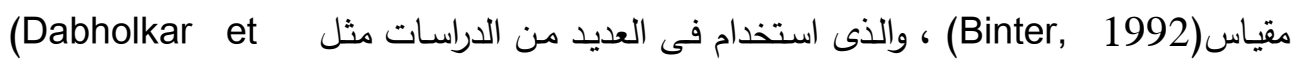

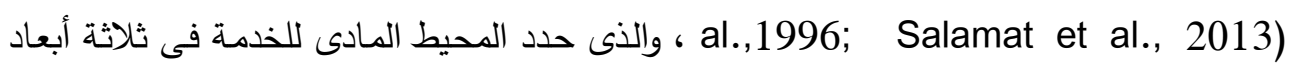

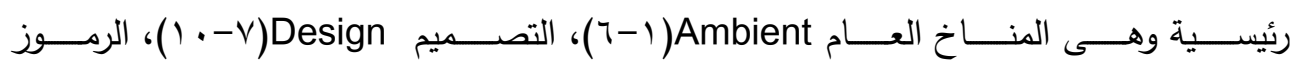

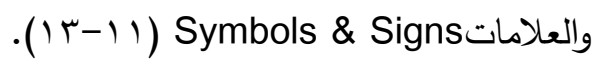

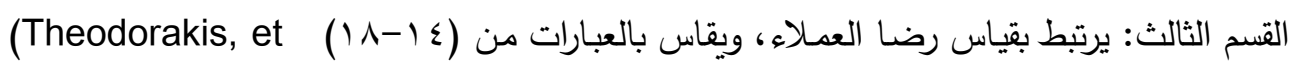

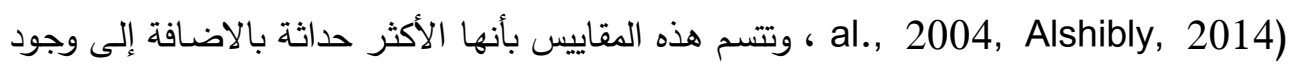
تشابه كبير بين معظم الدراسات الأخرى فى البنود التى وردت بهذين المقياسين.

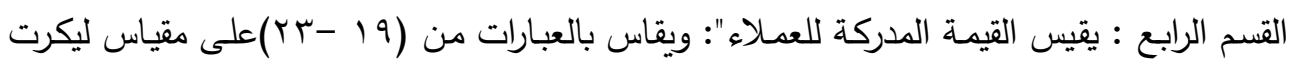
الخماسى (1996) (Brodie et al., 2009 ; Levesque and McDougall)

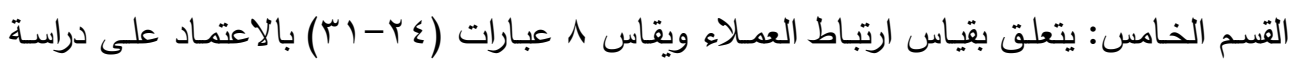
.(Brodie et al., 2011 ;So et al. 2012) ع -التحليل الإحصائى واختبار فروض الدراسة

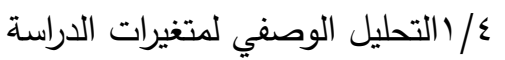

جدول (r) التحليل الوصفي لمتغيرات الدراسة

\begin{tabular}{|c|c|c|c|c|}
\hline معامل التفرطح & معامل الالتواء & الانحراف المعيارى & الوسط الحسابي & المتغيرات \\
\hline-.437 & -.377 & 1.05273 & 3.2789 & المناخ العام \\
\hline-.109 & -.684 & .79257 & 3.8033 & التصميم الداخلي \\
\hline-.449 & -.424 & .80100 & 3.6892 & الرموز والاشارات \\
\hline-.422 & -.378 & .58613 & 3.6363 & المحيط المادى للخدمة \\
\hline-.436 & -.500 & 1.04489 & 3.3235 & رضا العميل \\
\hline-.835 & -.449 & 1.09878 & 3.3994 & القيمة المدركة \\
\hline-.335 & -.599 & .98314 & 3.5033 & ارتباط العملاء \\
\hline
\end{tabular}


يتضح من الجدول(r) أن عينة البحث تميل إلى الموافقه إلى حد ما على المحيط الخدمى

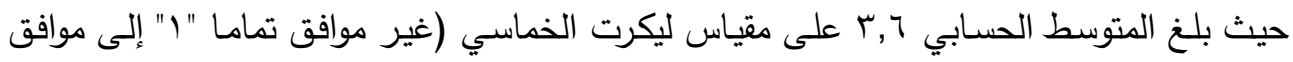

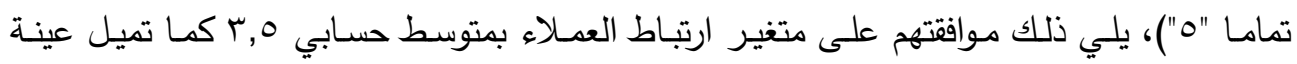

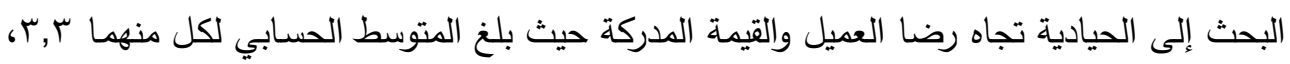

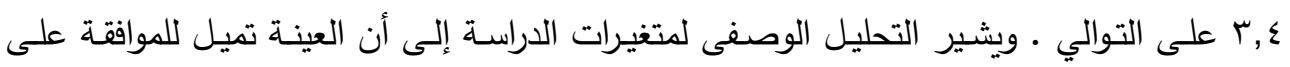

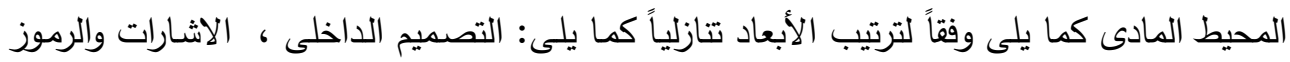

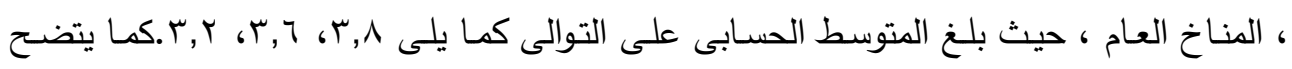

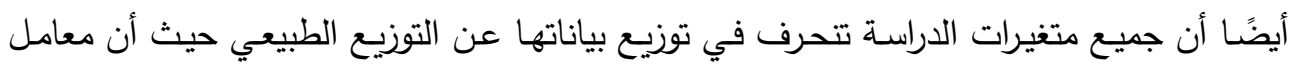

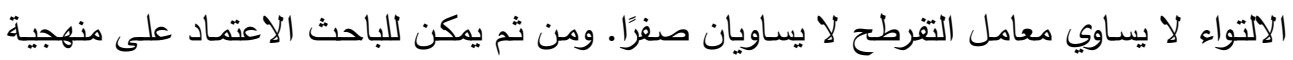

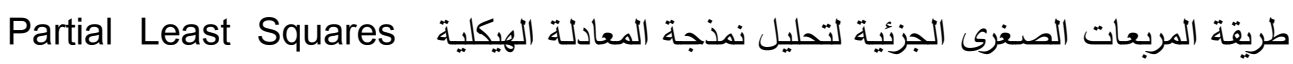
. Smart PLS وذلك ببرنامج Structural Equation Modelling

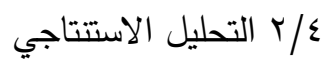
تم الاعتماد على مدخل المرحلتين Two stage approach في تحليل البيانات باستخدام

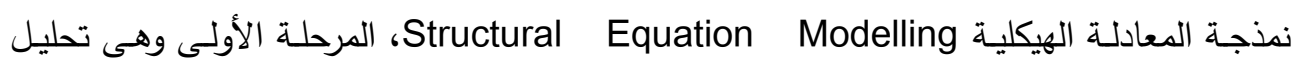
الصلاحية والثبات للبود قياس المتغيرات، والمرحلة الثانية تتمثل في اختبار فروض الدراسة (المباشرة

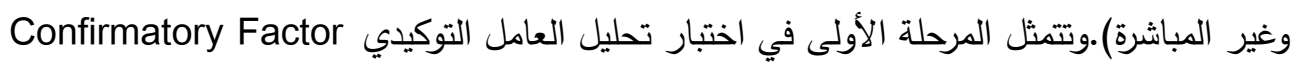
Analysis الصلاحية التقاربية Convergent Validity وذلك باستخدام مستخلص التباين المتوسط Average Variance Extracted (AVE)

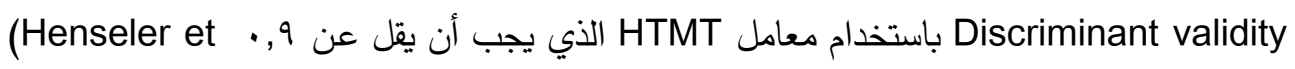

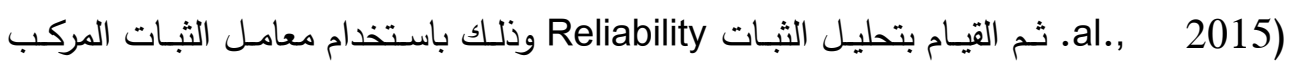
وكذلك معامل كرونباخ ألفا Composite reliability

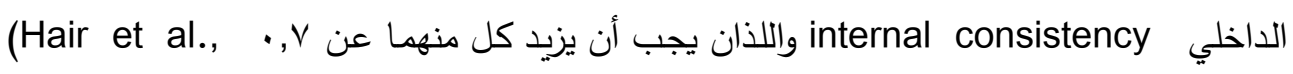
(2016 وذلك باستخدام برنامج ويوضح الشكل (r) نموذج القياس المحسن الذي تم تطويره لقياس متغيرات الدراسة تمهيداً لاختبار الفروض. كما يوضح الجدول (ץ) نتائج اختبار الصدق والثبات لمتغيرات الدراسة. 


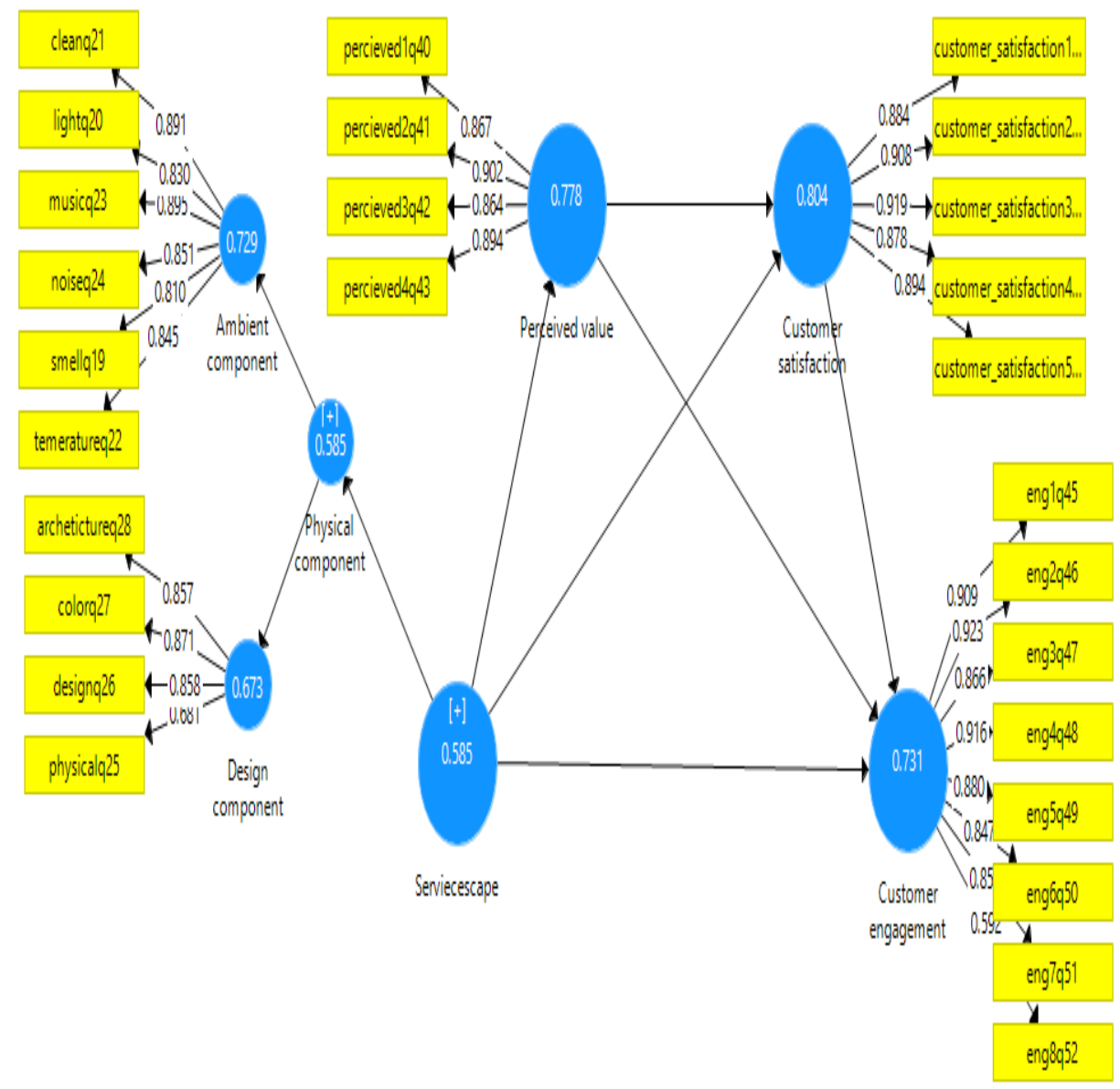

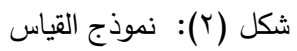

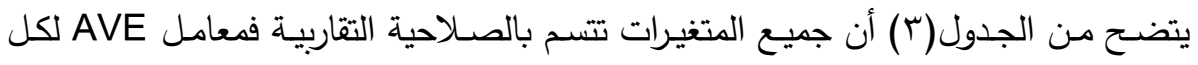

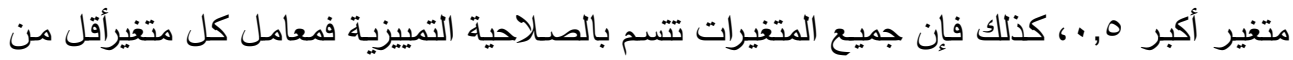

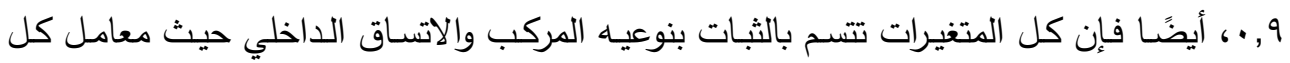

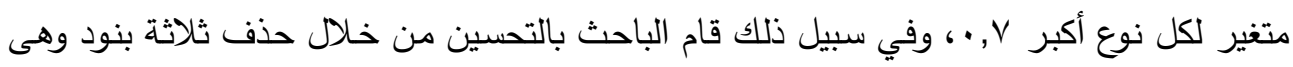

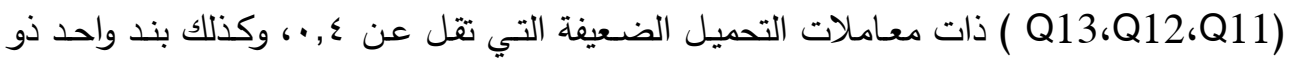
معامل تحميل متعددة على أكثر من متغير في نفس النموذج) ويمكن توضيح تلك البنود 


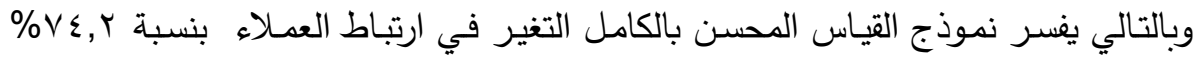
وهى نسبة تعد قوية، أي أن التغير في النموذج بمقدار وحدة واحدة يفسر التغير فى ارتباط العملاء

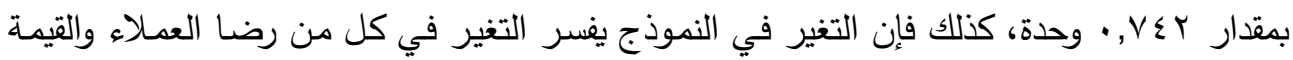

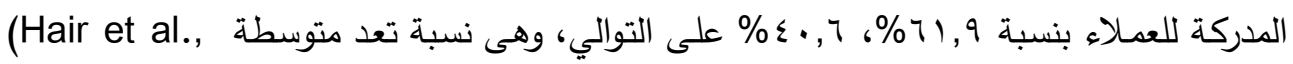
.2010; 2014)

جدول (r) نتائج الصدق والثبات

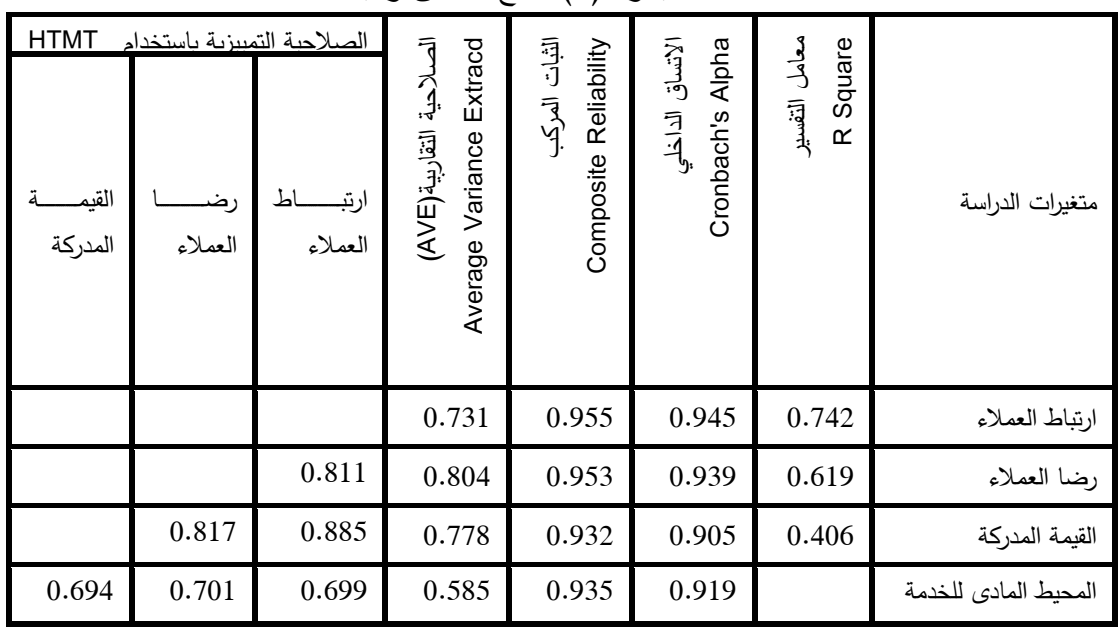

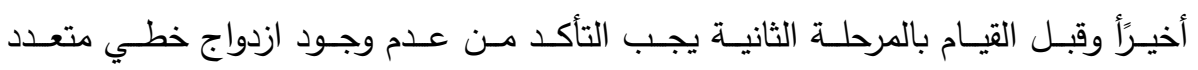
Multicollinearity Variance Inflation Factor (VIF) إلى 0 لكل متغيرن مستقلين معا، وهو ما يوضح عدم وجود ازدواج خطي متعدد بين المتغيرات

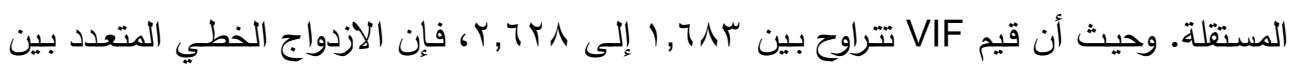

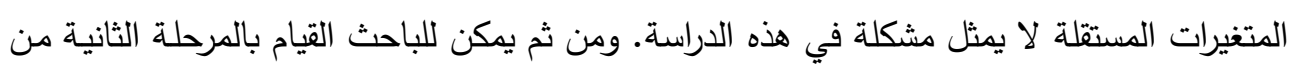

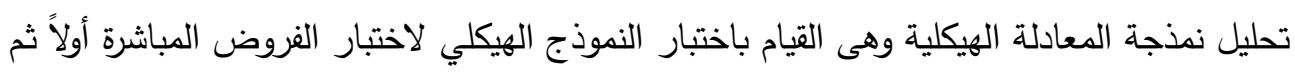

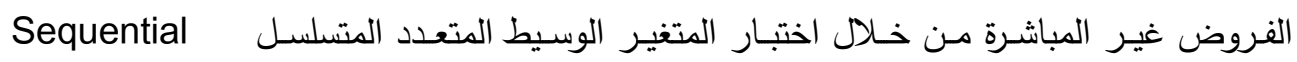
.multiple mediation test 
ف آختبار فروض الدراسة

فى الجزء التالى يمكن توضيح اختبار الفروض المباشرة وغير المباشرة كما يلى : جدول (乏) اختبار الفروض المباشرة

\begin{tabular}{|c|c|c|c|c|c|}
\hline النتيجة & درجة المعنوية & ت ت المحسوبة & بيتا & فروض الدراسة & \\
\hline قبول **** & 0.000 & 3.495 & 0.128 & المحيط المادى للخدمة-> ارتباط العملاء & ف1 \\
\hline قبول **** & 0.000 & 6.316 & 0.292 & المحيط المادى للخدمة -> رضا العملاء & فن \\
\hline قبول **** & 0.000 & 17.695 & 0.637 & المحيط المادى للخدمة -> التيمة المدركة & فـ \\
\hline قبول**** & 0.000 & 12.790 & 0.568 & القيمة المدركة -> رضا العملاء & فـ \\
\hline قبول*** * & 0.000 & 5.473 & 0.287 & رضا العملاء -> ارتباط العملاء & فنه \\
\hline قبول*** * & 0.000 & 10.271 & 0.529 & القيمة المدركة -> ارتباط العملاء & ف1 \\
\hline
\end{tabular}

* قبول الفرض عند مستوى معنوية أقل من 0 .,.

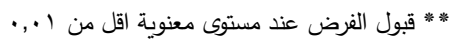

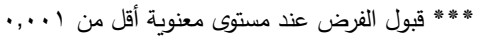

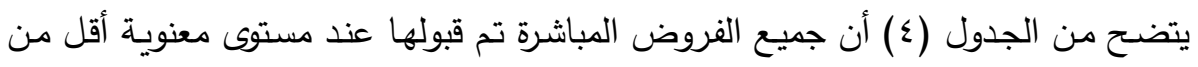

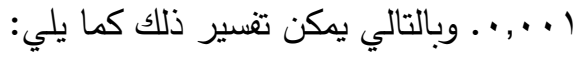
قبول الفرض الأول: يؤثر المحيط المادى لمراكز اللياقة البدنية تأثيراً ايجابياً فى ارتباط العملاء.

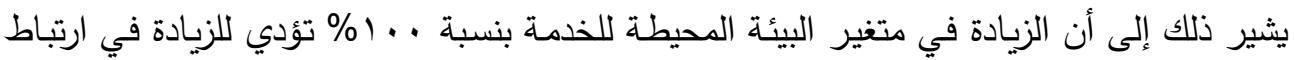

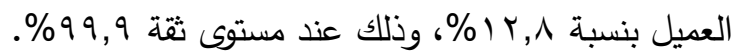

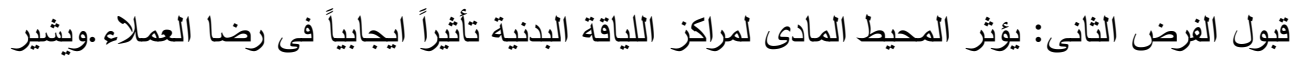

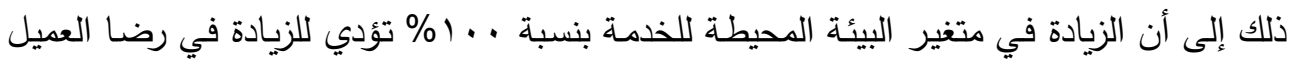

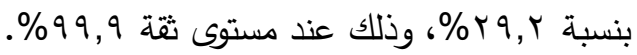
قبول الفرض الثالث:يؤثر المحيط المـادى لمراكز اللياقة البدنيـة تأثيراً ايجابياً فـى القيمـة المدركة

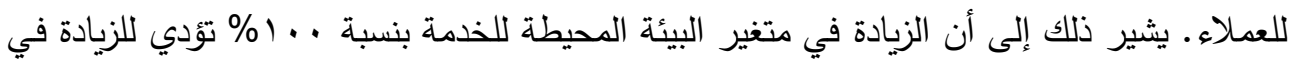

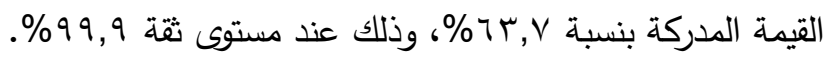

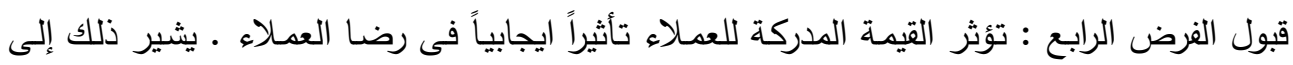

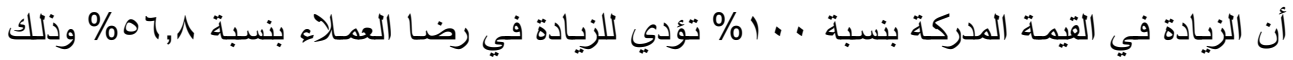

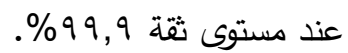
قبول الفرض الخامس: يؤثر رضا العملاء تأثيراً إيجابياً فى ارتباط العملاء. يشير ذلك إلى أن الزيادة

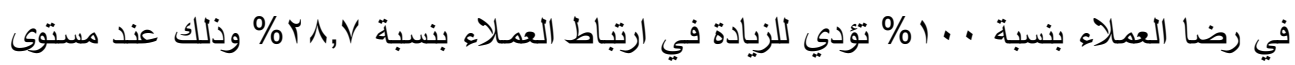
ثقة 99,9\%. 


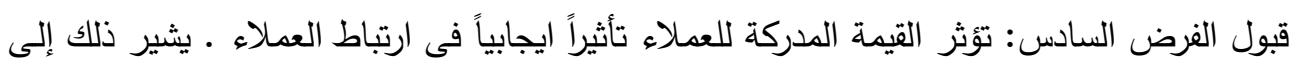

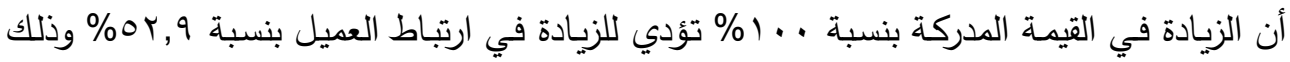

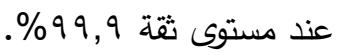
ومن ثم يمكن القيام باختبار العلاقات غير المباشرة والتي يمكن القيام بها. حيث اختبار المتغير

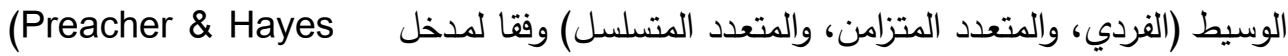

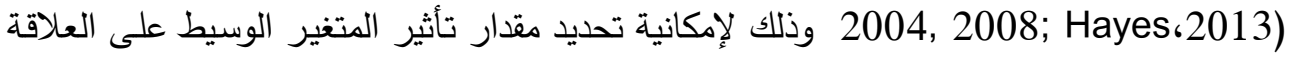
بين المتغير المستقل والمتغير التابع.

جدول (0) اختبار المتغير الوسيط الفردي(رضا العملاء)

\begin{tabular}{|c|c|c|c|c|c|}
\hline$\beta$ & & (رضا العميل) & & & (رضا العميل) \\
\hline $0.828^{* * * *}$ & \multirow{3}{*}{ القيمة المدركة-> ارتباط العملاء } & التأثير المباشر & $0.657^{* * * *}$ & \multirow{3}{*}{ البيئة المحيطة للخدمة -> ارتباط العملاء } & لتأثير المباشر \\
\hline $0.225^{* * * *}$ & & التأثير غير المباشر & $0.391^{* * * *}$ & & ل أتأثير غير المباشر \\
\hline $0.828^{* * * *}$ & & التأثير الكلي & $0.597^{* * *}$ & & ل التأثير الكلي \\
\hline تأثير جزئي & \multicolumn{2}{|c|}{$0.27=0.828 / .225=\mathrm{VAF}$} & تأثير جزئي & \multicolumn{2}{|c|}{$0.65=0.597 / 0.391=$ VAF } \\
\hline 0.734 & \multicolumn{2}{|c|}{ معامل التباين لارتباط العملاء ${ }^{2}$} & 0.631 & \multicolumn{2}{|c|}{ Rعل التباين لارتباط العملاء } \\
\hline
\end{tabular}

* ق قبول الفرض عند مستوى معنوية أقل من 0 .,.

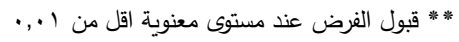

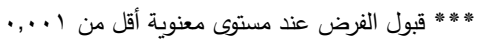

يتضـح من الجدول (0) الخاص باختبار المتغيرات الوسيطة قبول الفرض السـابع : يتوسط رضا

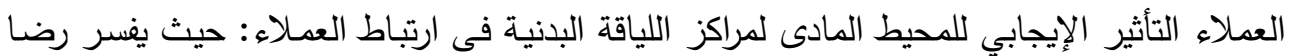

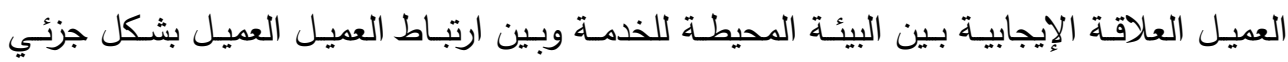

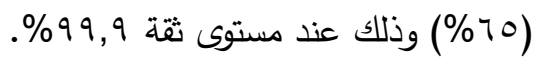

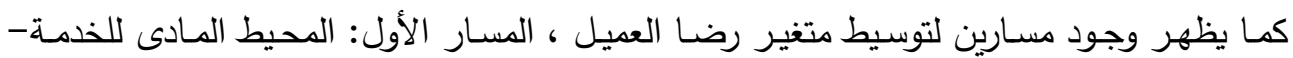

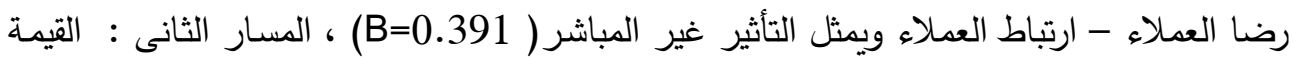
المدركة - رضا العملاء - ارتباط العملاء ويمثل التأثير غير المباشر ( B (B=0.225)، كما توضئح قيمة(Variance Accounted For (VAF)، التأثير الجزئى للقيمة المدركة كتمغير وسيط بماء يفسر العلاقة الايجابية بين المحيط المادى للخدمة وارتباط العملاء بنسبة 70\% 
جدول (؟) اختبار المتغير الوسيط الفردي(القيمة المدركة)

\begin{tabular}{|c|c|c|c|c|c|}
\hline$\beta$ & \multicolumn{2}{|l|}{ (القيمة الدركة) } & $\beta$ & \multicolumn{2}{|l|}{ إل القيمة الدركة) } \\
\hline $0.657 \cdots$ & \multirow{3}{*}{ المحيط المادى للذذمة -> ارتباط العلاء } & التأثير المباشر & $0.657^{\ldots \circ}$ & \multirow{3}{*}{ العيط المادى للذذمة -> رضا العبلاء } & 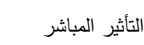 \\
\hline $0.441^{* \infty}$ & & التأثير غير المباشر & $0.362^{\cdots} \cdots$ & & التأثير غير المباشر \\
\hline $0.693^{* *}$ & & التأثير الكلي & $0.569^{* \ldots}$ & & 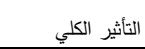 \\
\hline تاثئر جزئي & \multicolumn{2}{|c|}{$0.64=0.693 / 0.441=$ VAF } & تائر جزئي & \multicolumn{2}{|c|}{$0.64=0.569 / 0.362=$ VAF } \\
\hline 0.711 & \multicolumn{2}{|c|}{ معامل الثباين لارتباط العلاء R } & 0.620 & \multicolumn{2}{|c|}{ معامل التباين لرضا العملاء R } \\
\hline
\end{tabular}

" قبول الفرض عند مستوى معنوية أقل من 0 .,.

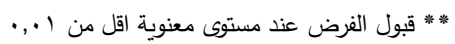

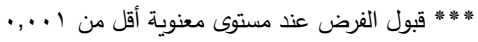

يتضح من جدول (7) قبول الفرض الثامن :تتوسط القيمة الددركة للعملاء التأثير الإيجابي للمحيط

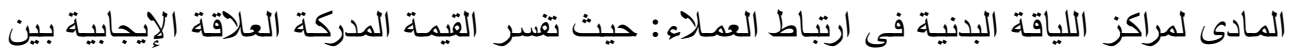

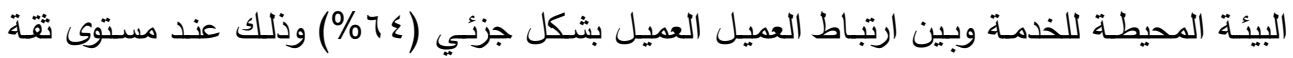

كما يظهر وجود مسارين لتوسيط متغير القيمة المدركة ، المسار الأول: المحيط المادى للخدمة-

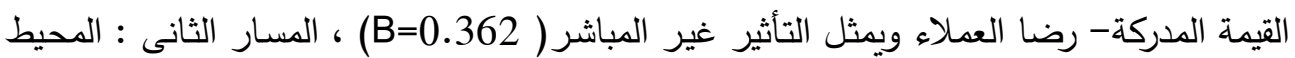

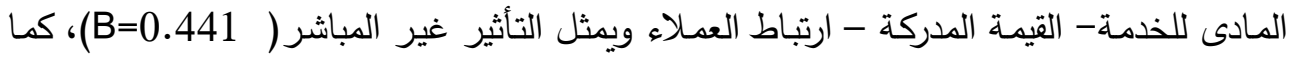
توضح قيمة)Variance Accounted For (VAF)، التأثير الجزئى للقيمة الددركة كتمغير وسيط

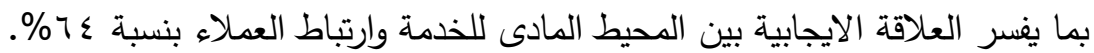
جدول (V) اختبار المتغير الوسيط المتعدد التزامني

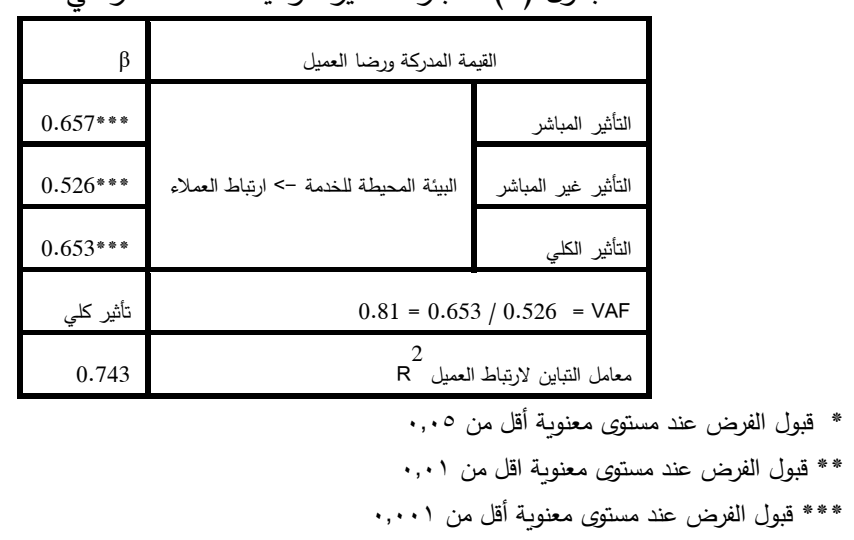


جدول (^) اختبار المتغير الوسيط المتعدد المتسلسل

\begin{tabular}{|c|c|c|}
\hline$\beta$ & \multicolumn{2}{|c|}{ القيمة المدركة ورضا العميل بوجود العلاقة بينهما } \\
\hline 0.657 **** & \multirow{3}{*}{ البيئة المحيطة للذدمة -> ارتباط العملاء } & التأثير المباشر \\
\hline $0.525^{* \text { **** }}$ & & التأثير غير المباشر \\
\hline $0.653^{\text {****** }}$ & & التأثير الكلي \\
\hline تأثير كلي & \multicolumn{2}{|c|}{$0.8=0.653 / 0.525=\mathrm{VAF}$} \\
\hline 0.742 & \multicolumn{2}{|c|}{ معامل التباين لارتباط العميل R } \\
\hline
\end{tabular}

"قبول الفرض عن مستوى معنوية أقل من 0 ., •

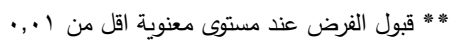

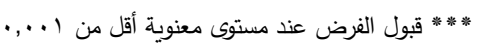

وللمقارنـة بين أى المتغيرات الوسيطة أفضل في تفسير العلاقـة بين البيئة المحيطـة للخدمـة وبين ارتباط العميل، يلجأ الباحث إلى معامل التباين الخاص بارتباط العميل، فزيـادة معامل التباين تمثل زيادة نسبة تفسير المتغير التابع من خلال النموذج ككل، ومن ثم فقد قام الباحث باختبار المتغير الوسـيط الفـردي، والمتعـدد المتزامن، والمتعـدد المتسلسـل للمقارنــة بـين البـدائل المختلفـة لتوليفـات المتغيرات الوسيطة معاً، واتضـح أن أفضل قرار يمكن للمديرين الاعتمـاد عليه هو الاعتمـاد على القيمة المدركة ورضـا العميل معاً لتفسير العلاقة الموجبة بين البيئة المحيطة للخدمـة وبين ارتباط العمـلاء. حيث أن نسبة تفسير هذه المتغيرات معًا IN\% أي أنها تتوسط كليًا العلاقة المفترضـة

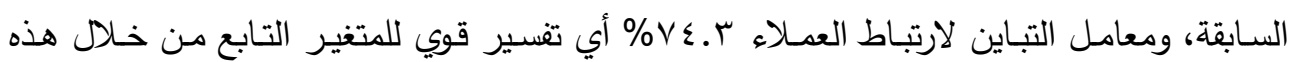
المتغيرات.

\section{سابعاً: مناقشة نتائج الدراسة}

يتضـح مـن نتائج التحليل الإحصـائى بالجدول (Y) أن المتوسطات الحسـابية لنتائج عينـة البحث تحصر بين (3.27)، (3.68) حيث تميل عينة الدراسـة بشكل عام للموافقة على البيئة المحيطة بالخدمة، ارتباط العملاء، القيمة المدركة، رضا العميل، ويمكن استتاج التحليل الإحصائي لبيانات

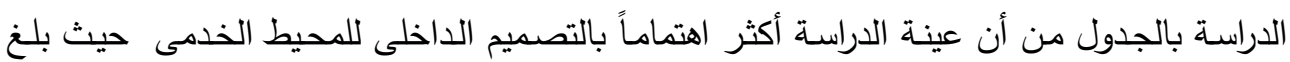
المتوسط الحسابى (3.8)، فى حين بلغ المناخ العام (3.27)،الرموز والاشـارات (3.68)، مما يدل على أن عينة الدراسة تولى اهتماما بالتصميم الداخلى لمركز اللياقة البدنية. تشير النتائج لوجود تأثير مباشر للمحيط المادى للخدمة على كل من القيمة المدركة ورضـا العملاء والارتباط كما يلى على التوالى(B=0.292)، B=0.637) )، (B=0.128 )، وذلك من خلال قياس 


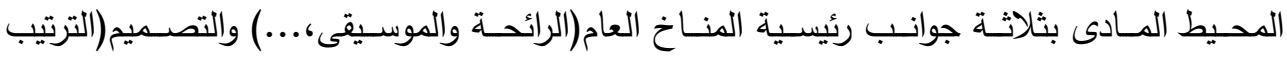

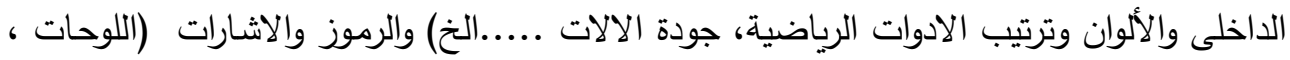

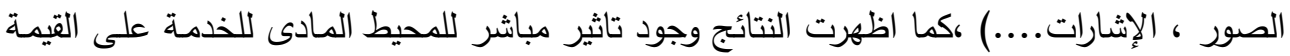
المدركة (B=0.637) ويدل ذلك على أن المحيط المادى لمراكز اللياقة يحقق قيمة مدركة للاعضاء

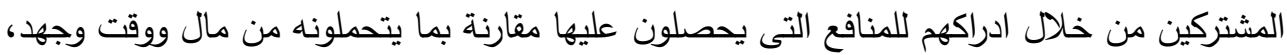
كما يمثل متغيرا أساسياً لتحقيق القيمة، بمعنى آخر كلما كان العميل أكثر إيجابية في إدراك البيئة

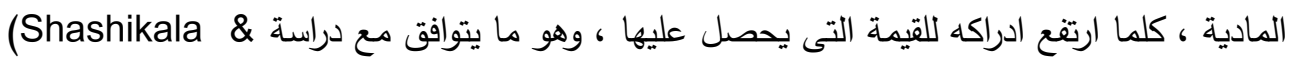
. Suresh , 2018) كما يظهر وجود تأثير مباشر للمحيط المادى للخدمة على رضا العملاء (B=0.292 )، ويدل ذلك

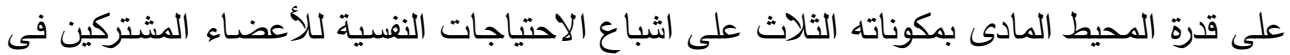

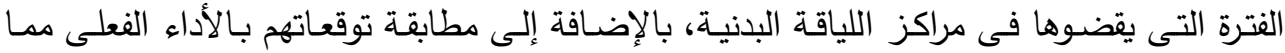

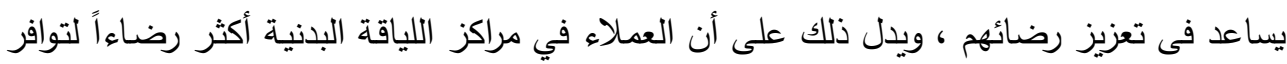

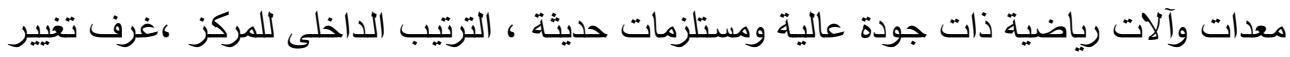

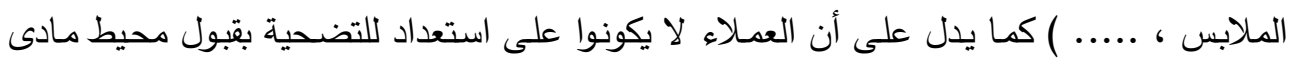

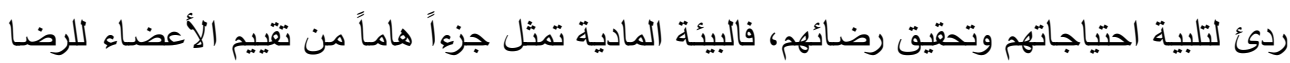

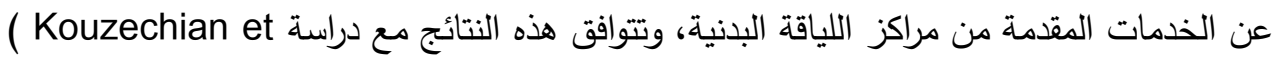
al., 2009; Ryu et al., 2012 ; Salamat et al., 2013) ويمكن استتاج ترتيب متغيرات الدراسة فى التأثير المباشر على ارتباط العملاء بمراكز اللياقة البدنية كما يلى على التوالى : القيمة المدركة(B=0.529) رضئل للخدمة(B=0.128) ، ويدل ذلك على أن العامل الأكثر تأثيراً فى تحقيق ارتباط العملاء هو ادراكهح

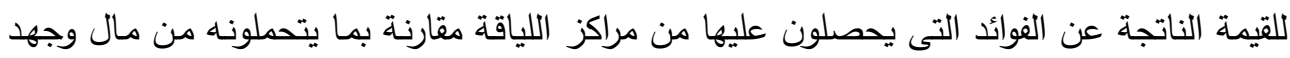

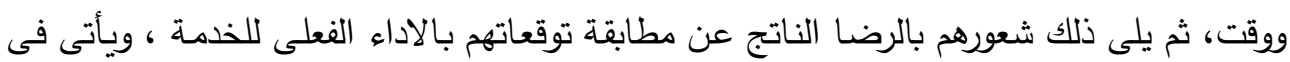
المرتبة الأخيرة ادراكهم للمحيط المادى للخدمة ويدل ذلك على دوف انه كلما كان العميل أكثر إيجابية في إدراك المؤشرات المادية للبيئة الخدمية ، كلما ارتفعت درجة ارتباطه بمركز اللياقة البدنية، وهذا يدل

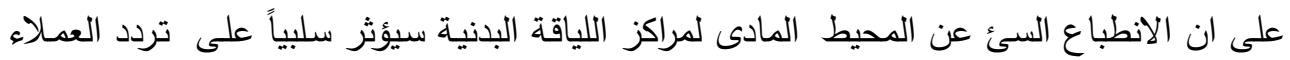
في الحضور بل انسحابهم إذا لم يتمكن مركز اللياقة البدنية من إدارة المحيط المادى بكفاءة. 
كمـا أظهـرت نتـائج الدراسـة أن القيمـة المدركـة كانت أكثر المتغيـرات تـأثيراً على رضـا العمـلاء

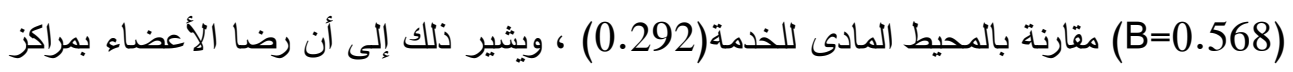

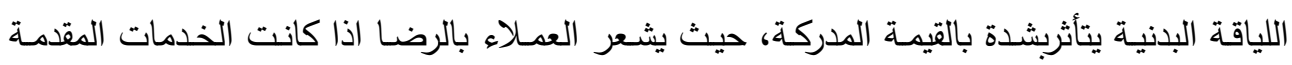

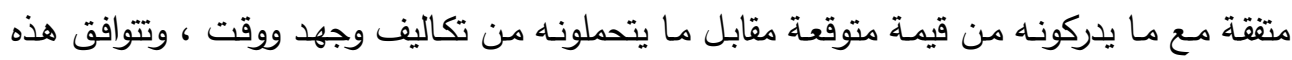

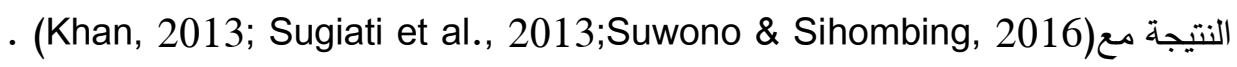

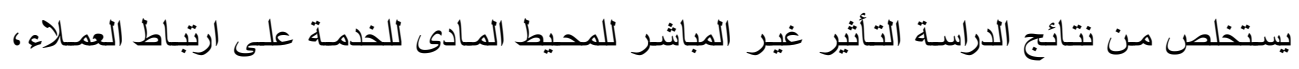

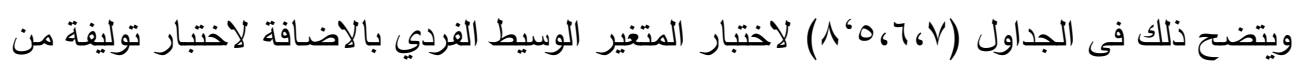

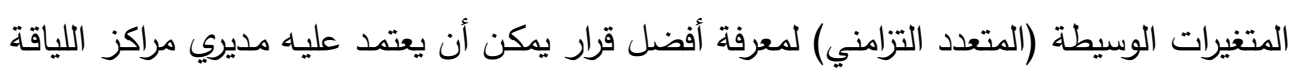

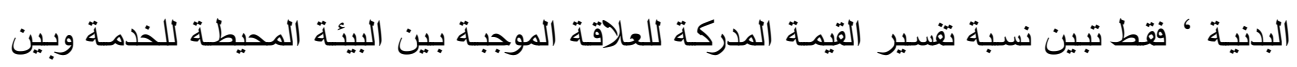

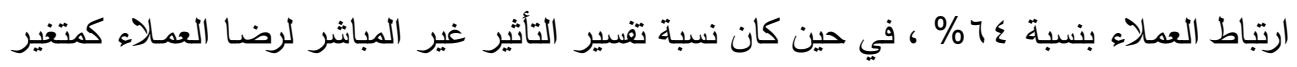

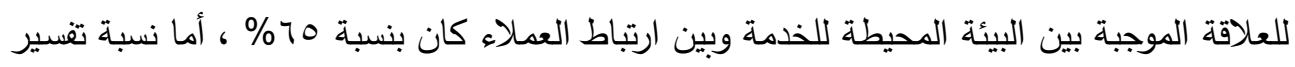

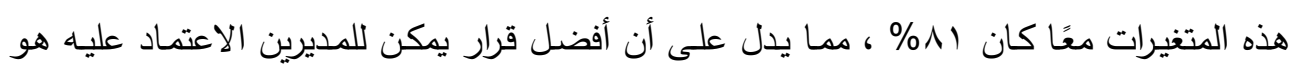

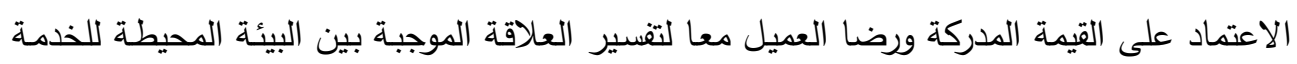
وبين ارتباط العملاء. وبمقارنة التأثير المباشر للمحيط المادى للخدمة والتأثير غير المباشر فى ارتباط العملاء ، يلاحظ

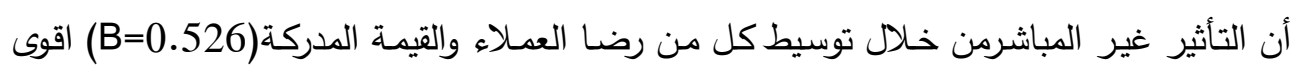

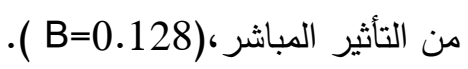

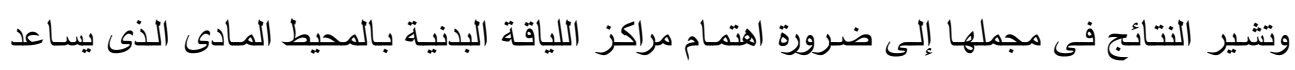

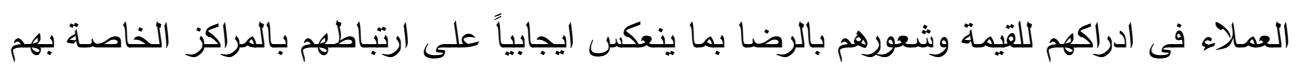

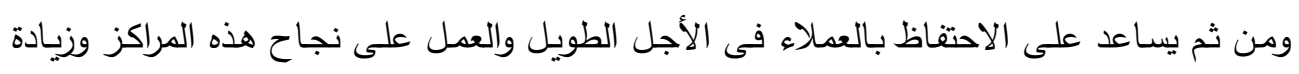
قدرتها التنافسية .

\section{تاسعاً: توصيات الدراسة}

في ضوء مناقشـة نتائج الدراسـة يتسني للباحث تقديم مجموعة من التوصيات التئه التي يمكن أن تعود

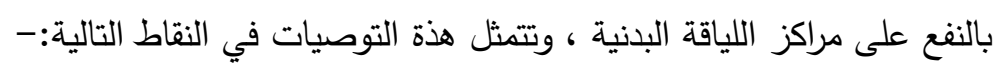

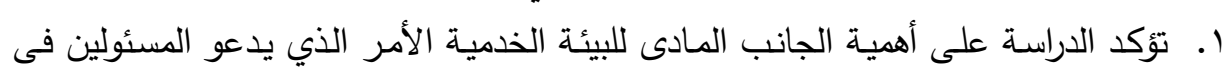

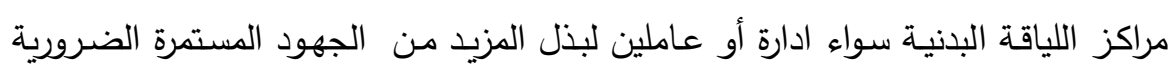

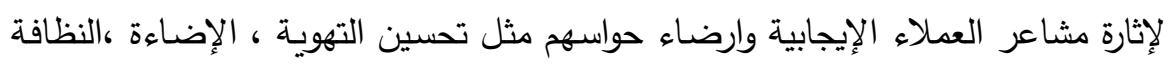


، تحديث المرافق، توفير مناخ صحى، وتوفير مساحة كافية للحركة ، وإنشاء بيئة مادية

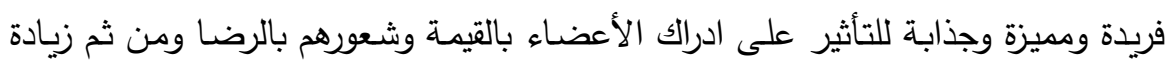
الارتباط بالمراكز الرياضية.

r. العمل على استيعاب المتطلبات المتزايدة والمتطورة بشكل متزايد من قبل العملاء، والعمل العاصل

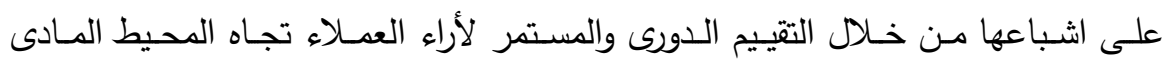

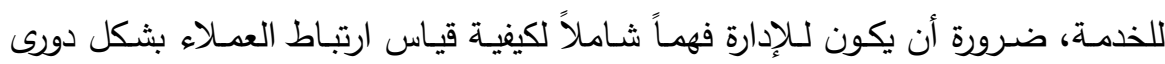

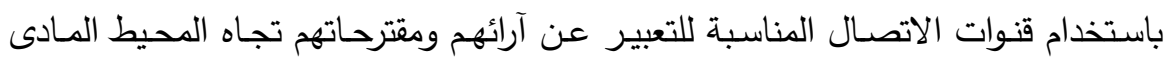

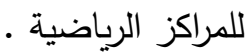
r. ضرورة تدريب العاملين ليكون أكثر اهتماماً بالنظافة الشخصية ، والالتزام بقواعد الملابس لـابس

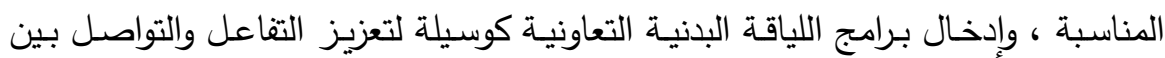

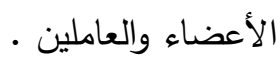
ع. حرص الادارة على الصيانة الدوريـة للمكونات المختلفة للدحيط المادى للخدمة لتجنب القصور فيها .

\section{عاشراً: الدراسات المستقبلية}

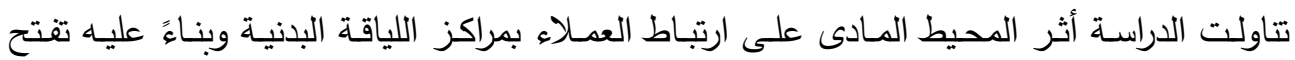

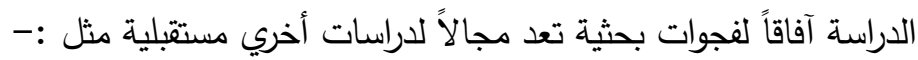

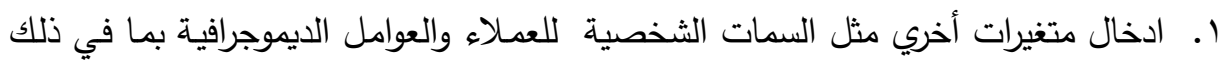

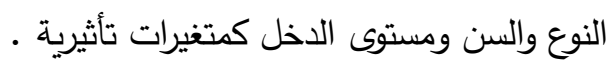

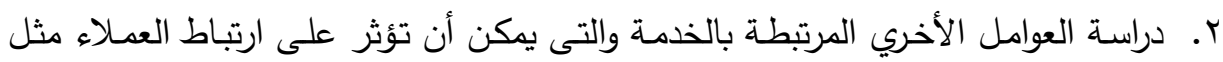
العوامل الاجتماعية (سلوك العاملين والعملاء).

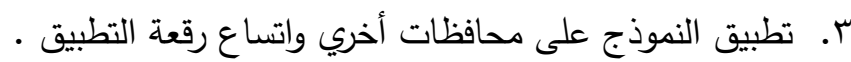

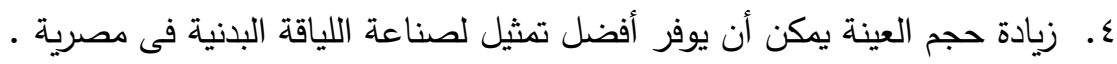

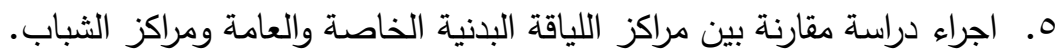

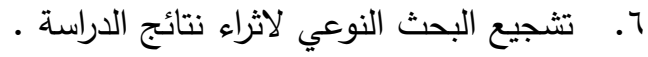
V. تطبيق نموذج الدراسة على العديد من الخدمات.(الفنادق - كورسات تعليم اللغة - البنوك) 


\section{Reference}

- Ahn, J., \& Back, K. J. (2018). Antecedents and consequences of customer brand engagement in integrated resorts. International Journal of Hospitality Management, 75, 144-152.

- Ali, F., \& Amin, M. (2014). The influence of physical environment on emotions, customer satisfaction and behavioural intentions in Chinese resort hotel industry. Journal for Global Business Advancement, 7(3), 249-266.

- Alshibly, H. H. (2014). A free simulation experiment to examine the effects of social commerce website quality and customer psychological empowerment on customers' satisfaction. Journal of Business Studies Quarterly, 5(4), 21-40.

- Ariff, M., Fen, H. S \& Ismail, K. (2012). Relationship Between Customer' Perceived Values, Satis- faction and Loyalty of Mobile Phone Users. Review of Integrative Business and Economics Research, 1 (1), 126-135.

- Ariffin, A. A. M., Nameghi, E. N., \& Zakaria, N. I. (2013). The effect of hospitableness and servicescape on guest satisfaction in the hotel industry. Canadian Journal of Administrative Sciences , 30(2), 127-137.

- Ariffin, H. F., Bibon, M. F., \& Abdullah, R. (2011). Restaurant's atmospheric elements: What the customer wants. Journal of Asian Behavioural Studies, 1(2), 33-43.

- Ballantine, P. W., Jack, R., \& Parsons, A. G. (2010). Atmospheric cues and their effect on the hedonic retail experience. International Journal of Retail \& Distribution Management, 38(8), 641-653.

- Bitner, M. J. (1992). Servicescapes: The impact of physical surroundings on customers and employees. Journal of Marketing, 56(2), 57-71.

- Brodie, R. J., Hollebeek, L. D., Jurić, B., \& Ilić, A. (2011). Customer engagement: Conceptual domain, fundamental propositions, and implications for research. Journal of service research, 14(3), 252-271.

- Brodie, R. J., Ilic, A., Juric, B., \& Hollebeek, L. (2013). Consumer engagement in a virtual brand community: an exploratory analysis. Journal of Business Research, 66(1), 105-114.

- Brodie, R.J., Hollebeek, L.D., Juric', B. and Ilic', A. (2011). Customer engagement. Journal of Service Research, Vol. 14 No. 3, 252-271.

- Brodie, R.J., Whittome, J.R.M. and Brush, G.J. (2009). Investigating the service brand: a customer value perspective. Journal of Business Research, Vol. 62 No. 3, 345-355. 
- Calder, B.J., Malthouse, E.C. and Schaedel, U. (2009). An experimental study of the relationship between online engagement and advertising effectiveness. Journal of Interactive Marketing, Vol. 23 No. 4321-331.

- Çelik, A. D. K. (2015). Bank hospitality and servicescape evaluation by bank customers and their effects on satisfaction,Unpublished Master's dissertation, Eastern Mediterranean University (EMU)-Doğu Akdeniz Üniversitesi (DAÜ).

- Chen, A., Peng, N., \& Hung, K. P. (2015). The effects of luxury restaurant environments on diners' emotions and loyalty. International Journal of Contemporary Hospitality Management, 27(2), 236-260.

- Cheon, Y. S. (2016). A Study on the Relationship among Physical Environment of Festivals, Perceived Value, Participation Satisfaction, and Festival Image. International Review of Management and Marketing, 6(5S), 281-287.

- Conceptual model. Journal of Product \& Brand Management,( 2014) Mar 11;23(1):62-74.

- Countryman, C. C., \& Jang, S. (2006). The effects of atmospheric elements on customer impression: The case of hotel lobbies. International Journal of Contemporary Hospitality Management, 18(7), 534-545.

- Dabholkar, Praitaiba, Dayle I. Thorpe, and Joseph O. Rentz (1996). A Measure of Service Quality for Retail Stores: Scale Development and Validation. Journal of the Academy of Marketing Science, 24(1), 3-16 .

- Demoulin, N. T. M. (2011). Music congruency in a service setting: The mediating role of emotional and cognitive responses. Journal of Retailing and Consumer Services, 18(1), 10-18.

- Dovaliene, A., Masiulyte, A., \& Piligrimiene, Z. (2015). The relations between customer engagement, perceived value and satisfaction: the case of mobile applications. Procedia-Social and Behavioral Sciences, 213, 659-664.

- Fernandes, T., \& Neves, S. (2014). The role of servicescape as a driver of customer value in experience-centric service organizations: the Dragon Football Stadium case. Journal of Strategic Marketing, 22(6), 548-560.

- Ha, J., \& Jang, S. (2012). The effects of dining atmospherics on behavioral intentions through quality perception. Journal of Services Marketing, 26(3), 204-215.

- Hai Quynh, Ngo, Thanh Hoai, Nguyen, Pham Ngoc Nha, Ngo, Gi-Du, Kang,(2018). The Influence of Perceived Value, Brand Image and Corporate Reputation on Customer Engagement and Customer Loyalty. 
Scholars Journal of Economics Business and Management (SJEBM), 136146.

- Hapsari R, Clemes MD, Dean D.(2017). The impact of service quality, customer engagement and selected marketing constructs on airline passenger loyalty. International Journal of Quality and Service Sciences, 20,9(1):21-40.

- Hollebeek, L.D., Glynn, M.S. and Brodie, R.J. (2014). "Consumer brand engagement in social media: conceptualization, scale development and validation". Journal of Interactive Marketing, 28 (2), 149-165.

- Hooper, D., Coughlan, J., \& Mullen, M. R. (2013). The servicescape as an antecedent to service quality and behavioural intentions. Journal of Services Marketing, 27(4), 271-280.

- IHRSA(2017), Global Report 2017, Retrieved December 12, 2018 fromhttp://www.healthclubmanagement.co.uk/health-club-managementfeatures/Findings-from-the-IHRSA-Global-Report-2017/31950

- IHRSA(2017), Global Report 2017, Retrieved December 12, 2018 fromhttps://www.ihrsa.org/about/media-center/press-releases/ihrsa-2018global-report-club-industry-revenue-totaled-87-2-billion-in-2017 /Global Report: The State of the Health Club Industry

- Ishaq, M. I., Bhutta, M. H., Hamayun, A. A., Danish, R. Q., \& Hussain, N. M. (2014). Importance of servicescape in services industries. Journal of Service Research, (4)2-13.

- Jain, R., \& Bagdare, S. (2011). Music and consumption experience: a review. International Journal of Retail \& Distribution Management, 39(4), 289-302.

- Jang, S., Liu, Y. and Namkung, Y. (2011). Effects of authentic atmospherics in ethnic restaurants: investigating Chinese restaurants. International Journal of Contemporary Hospitality Management, 23(5), 662-680.

- Kearney, T., Coughlan, J., \& Kennedy, A. (2012). An exploration of the effects of the servicescape on customer and employee responses in a grocery retail context. Irish Journal Of Management,71-91.

- Kim, K. T., Bae, J., Kim, J. C., Lee, S., \& Kim, K. T. (2016). The Servicescape in the fitness center: measuring fitness center's services. International Journal of Sport Management Recreation \& Tourism, 21(1), 1-20. 
- Kim, N. and Lee, M. (2012). Other customers in a service encounter: examining the effect in a restaurant setting". Journal of Services Marketing, Vol. 26 No. 1, 27-40.

- Kouzechian H, GoharRostami H, Ehsani M (2009). A Study of Customers Satisfaction with Private and Public Fitness Clubs in Tehran. Sport Management, 1-37.

- Kumar, I., Garg, R., \& Rahman, Z. (2010). Influence of retail atmospherics on customer value in an emerging market condition. Great Lakes Herald, 4(1), 1-9.

- Lee, S. Y., \& Kim, J. H. (2014). Effects of servicescape on perceived service quality, satisfaction and behavioral outcomes in public service facilities. Journal of Asian Architecture and Building Engineering, 13(1), 125-131.

- McDougall GH, Levesque T. (2000). Customer satisfaction with services: putting perceived value into the equation. Journal of services marketing, 14(5):392-410.

- Medabesh, A. and Upadhyaya, M. (2012). Servicescape and customer substantiation of star hotels in India's Metropolitan City of Delhi. Journal of Marketing \& Communication , 8 (2), 39-47.

- Miles, P., Miles, G. and Cannon, A. (2012). Linking servicescape to customer satisfaction: exploring the role of competitive strategy. International Journal of Operations and Production Management, 32 (7), 772-795.

- Moon, H., Yoon, H. J., \& Han, H. (2017). The effect of airport atmospherics on satisfaction and behavioral intentions: Testing the moderating role of perceived safety. Journal of Travel \& Tourism Marketing, 34(6), 749-763.

- Ong, D. L. T., \& Yap, W. X. (2017). The impact of fitness center servicescape on individual behavior: The mediating role of emotional response. Journal of Global Sport Management, 2(2), 128-142.

- Oztas, M., Sevilmis, A., \& Sirin, E. F. (2016). The relationship of atmosphere, satisfaction, and loyalty: Sample of a fitness center. Turkish Journal of Sport and Exercise, 18(2), 103-112.

- Payne, A \& Holt, S. (2001). Diagnosing Customer Value: Integrating the Value Process and Re- lationship Marketing.Bristish. Journal of Management, 12: 159-182.

- Polyakova, O., \& Mirza, M. T. (2016). Service quality models in the context of the fitness industry. Sport, Business and Management. An International Journal, 6(3), 360-382. 
- Pride William m. \& O.C. Ferrell . (2001). Marketing: Concepts and Strategies", Poston: Houghton Mifflin Co.

- Quynh .Hai, Ngo, Thanh Hoai, Nguyen, Pham Ngoc Nha, Ngo, Gi-Du, Kang,(2018). The Influence of Perceived Value, Brand Image and Corporate Reputation on Customer Engagement and Customer Loyalty. Scholars Journal of Economics, Business and Management (SJEBM), 136-146.

- Rashid, N. M., Ma'amor, H., Ariffin, N., \& Achim, N. A. (2015). Servicescape: Understanding how physical dimensions influence Exhibitors Satisfaction in Convention Centre. Procedia-Social and Behavioral Sciences, 211, 776-782.

- Rika, O. (2015). The Effect of Quality Dimensions on Customer Perceived Value, Restaurant Image, Customer Satisfaction and Behavioral Intentions (Study on the Xing Wang Resto).

- Rozenes, S., \& Cohen, Y. (Eds.). (2017). Handbook of Research on Strategic Alliances and Value Co-Creation in the Service Industry. IGI Global.

- Salamat, N., Farahani, A\&Salamat, F.( 2013). Custom- er Satisfaction in Private and Public Fitness Clubs in North ofIran.African . Journal of Business Management, 7(18): 1826-1832.

- Schaufeli, W.B., Salanova, M., González-Romá, V. and Bakker, A.B. (2002). The measurement of engagement and burnout: a two sample confirmatory factor analytic approach. Journal of Happiness Studies, Vol. 3 No. 1,. 71-92.

- Shashikala R. \& Suresh A. M. (2018). Impact of Servicescape on Customer Perceived Value in Fine Dining Restaurants. Amity Business Review, 19(1), 33-46.

- So, K.K.F., King, C. and Sparks, B. (2012). Customer engagement with tourism brands: scale development and validation. Journal of Hospitality \& Tourism Research, 38 (3), 304-329.

- Sprott, D., Czellar, S. and Spangenberg, E. (2009). The importance of a general measure of brand engagement on market behavior: development and validation of a scale. Journal of Marketing Research, 46 (1), 92-104.

- statista (2017), Africa \& Middle East health \& fitness club industry revenue by country in 2017 (in million U.S. dollars), Retrieved December 12,2018, from :

https://www.statista.com/statistics/252920/health-club-revenue-africamiddle-east. 
- statista (2017),Number of health/fitness clubs in Africa and the Middle East in 2016, by country, Retrieved December 12, 2018, from https://www.statista.com/statistics/308789/health-club-amount-in-africaand-the-middle-east-countries/

- Sugiati, T., Thoyib, A., Hadiwidjoyo, D \& Setiawan, M. (2013).The Role of Customer Value on Satisfaction and Loyalty (Study on Hypermart'sCustomers). International Journal of Business and Management Invention, 2, 65-70.

- Suwono, L. V., \& Sihombing, S. O. (2016). Factors Affecting Customer Loyalty of Fitness Centers: An Empirical Study. Journal Dinamika Manajemen, 7(1), 45-55.

- Sweeney, J. C., \& Soutar, G. N. (2001). Consumer perceived value: The development of a multiple item scale. Journal of Retailing, 77, 203-220.

- Theodorakis, N., Alexandris, K., Rodrigues, P. M. M., \& Sarmento, P. J. (2004). Measuring customer satisfaction in the context of health clubs in Portugal. International Sports Journal, 8, 44-53.

- Van Doorn, J., Lemon, K.N., Mittal, V., Nass, S., Pick, D., Pirner, P. and Verhoef, P.C. (2010). Customer engagement behavior: theoretical foundations and research directions. Journal of Service Research, 13 (3), 253-266.

- Vivek, S.D., Beatty, S.E. and Morgan, R.M. (2012). Customer engagement: exploring customer relationships beyond purchase. The Journal of Marketing Theory and Practice, 20 (2), 122-146.

- Vivek,S.D.,Beatty,S.E.,Dalela,V.andMorgan,R.M.(2014).A generalized multidimensional scale for measuring customer engagement". Journal of Marketing Theory and Practice, Vol. 22 No. 4, 401-420.

- Wakefield, K., \& Blodgett, J. (1996). The effect of the servicescape on customers' behavioral intentions in leisure service settings. Journal of Services Marketing, 10(6), 45-61.

- Zeithaml, V. A. (1988). Consumer perceptions of price, quality, and value: a means-end model and synthesis of evidence. Journal of marketing, 52(3), 2-22.

- Zeithaml, Valarie A., Bitner, Mary Jo and Dwayne D. Gremler. (2013). Services Marketing. Integrating Customer Focus across the Firm, 6th Edition, New York: McGraw-Hill Irwin. 
ملحق (1) : قائمة الاستقصاء

الرجاء الإجابة على جميع الأسئلة لذا يرجى عدم ترك أى سؤال دون إجابة

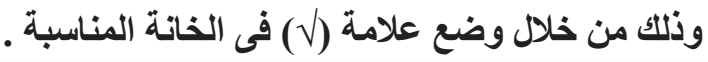

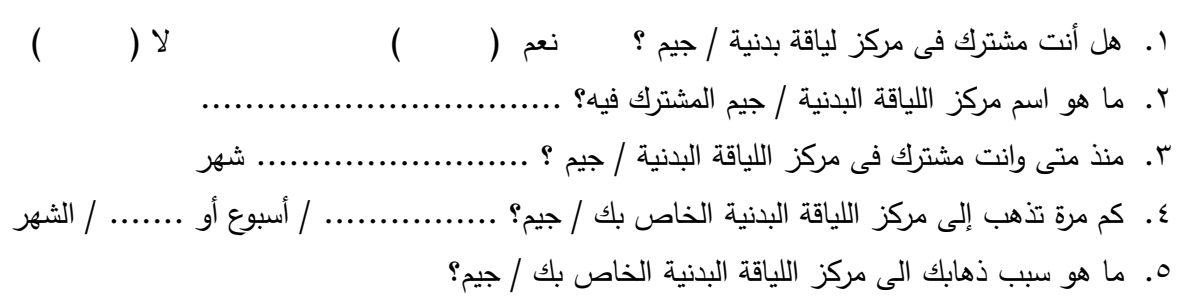

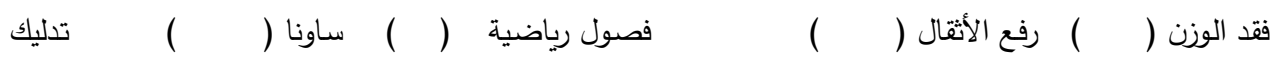

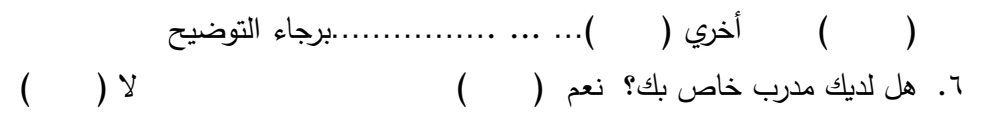

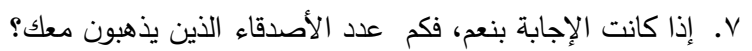

القسم الأول : رأيك عن الجيم . ألمأ.

إلى أى مدى توافق أو لا توافق على العبارات التالية بالنسبة للجيم ؟ لاوبم

\begin{tabular}{|c|c|c|c|c|c|}
\hline موافق & موافق & 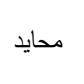 & 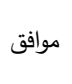 & تماماً & 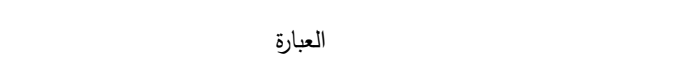 \\
\hline 1 & $r$ & r & $\varepsilon$ & 0 & 1. الرائحة في الجيم جيدة . \\
\hline 1 & r & r & $\varepsilon$ & 0 & r. الاضاءة مربحة للغاية. \\
\hline 1 & r & r & $\varepsilon$ & 0 & r. الجيم نظيف. \\
\hline 1 & r & r & $\varepsilon$ & 。 & ع. الجو لطيف (درجة الحرارة مناسبة). \\
\hline 1 & r & r & $\varepsilon$ & 0 & ه. الموسيقى في الجيم تسعدنى. \\
\hline 1 & $r$ & $r$ & $\varepsilon$ & 0 & 7. الضوضاء في الجيم يمكن تحملها . \\
\hline 1 & $r$ & r & $\varepsilon$ & 0 & V. الالوان في الجيم هادئة. \\
\hline 1 & $r$ & r & $\varepsilon$ & 0 & ^. توجد أجهزة رباضية ذات جودة مرتفعة. \\
\hline 1 & r & r & $\varepsilon$ & 0 & 9. الترتيب الداخلي للجيم مربح. \\
\hline 1 & r & r & $\varepsilon$ & 0 & • ا.تتظيم ادوات وأجهزة اللياقة البدنية مناسب. \\
\hline 1 & r & r & $\varepsilon$ & 0 & 11.توجد لوحات ارشادية في المكان المناسب. \\
\hline 1 & r & r & $\varepsilon$ & 0 & r ا.تساعدنى اللوحات الارشادية فى الدخول والخروج من الجيم. \\
\hline 1 & r & r & $\varepsilon$ & 。 & سا .الصوروالرسومات على الجدران جذابة. \\
\hline
\end{tabular}


القسم الثانى : الى اي مدى انت راض عن الجيم ؟

\begin{tabular}{|c|c|c|c|c|c|}
\hline موافق & غوافق & محايد & موافق & تماماً & العبارة \\
\hline 1 & r & r & $\varepsilon$ & 。 & 1. يقدم لى هذا الجيم ما أحتاج إليه بالضبط. \\
\hline 1 & r & r & $\varepsilon$ & 。 & r. بـ يلبي هذا الجيم توقعاتي تماءًا. \\
\hline 1 & $r$ & $r$ & $\varepsilon$ & $\circ$ & ه. أنا راض عن الذدمات التى يقدمها هذا الجيم . \\
\hline 1 & r & r & $\varepsilon$ & 。 & †. أنا سعيد بالجهودالتي يقدمها الجيم اتجاه العملاء. \\
\hline 1 & r & r & $\varepsilon$ & 。 & V. اعتبراختاري للتعامل مع هذا الجيد اختاراً سليماً. \\
\hline
\end{tabular}

القسم الثالث : إلى أى مدى يحقق للك الجيم الحالى المنافع التالية:

\begin{tabular}{|c|c|c|c|c|c|}
\hline غوافير & موافق & محايد & موافق & تماماً - موافق & العبارة \\
\hline 1 & $r$ & $r$ & $\varepsilon$ & 0 & ᄉ.يقدم هذا الجيم خدمات ممتازة مقارنة بالسعر المدفوع. \\
\hline 1 & r & r & $\varepsilon$ & $\circ$ & 9. مل ذقارنة بالمجهود والوقت والاموال الدنفقة على الجيم فان الخدمات تفوق \\
\hline 1 & $r$ & $r$ & $\varepsilon$ & 0 & • ا.إلى حد ما الذذمات التى تقدم من الجيم متطورة مقارنة بالسعر. \\
\hline 1 & r & r & $\varepsilon$ & $\circ$ & 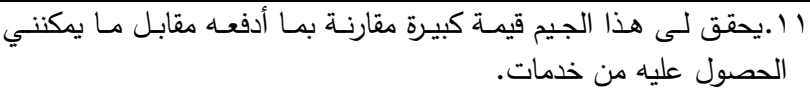 \\
\hline 1 & r & r & $\varepsilon$ & 。 & r با.يقدم لى هذا الجيم المزيد من الخدمات . \\
\hline
\end{tabular}

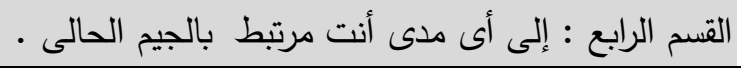

\begin{tabular}{|c|c|c|c|c|c|}
\hline 1 & r & r & $\varepsilon$ & 。 & rا.انا فخور بكونى عضو فى هذا الجيم. \\
\hline 1 & r & r & $\varepsilon$ & 。 & ـ (. عندما يشيد شخص ما بهذا الجيم يبذو وكأنه مجاملة شخصية لى. \\
\hline 1 & r & r & $\varepsilon$ & 。 & 10. لا استطيع ان ابتعد عن هذا الجيم. \\
\hline 1 & $r$ & r & \{ & o & 7 ا.أنا اهتم كثيرا بالمعلومات حول هذا الجيم \\
\hline 1 & r & r & $\varepsilon$ & 0 & V V ا.تحل اي مشكلة فى الجيم بشكل مرضى وعادل. \\
\hline 1 & r & r & $\varepsilon$ & 0 & 11 ا.أجد هذا الجيم أفضل من غيره من المنافسين . \\
\hline 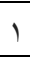 & r & r & $\varepsilon$ & $\circ$ & 9 19.لا استطيع التعامل مع اي جيم اخر بخلاف الجيم الحالى. \\
\hline e & r & r & $\varepsilon$ & 。 & •r.Y لا يمكنى قول أي كلمة سلبية عن هذا الجيم. \\
\hline
\end{tabular}

القسم الخامس : بيانات شخصية

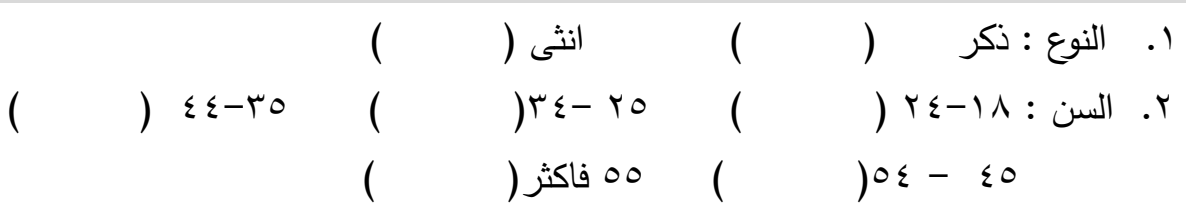

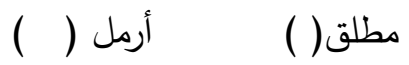

r. الحالة الاجتماعية: اعزب ( ) متزوج( ) شكراً لحسن تعاونكم 